\title{
Transmembrane Prolyl 4-Hydroxylase is a Novel Regulator of Calcium Signaling in Astrocytes
}

\author{
DNadiya Byts, ${ }^{1}$ DSubodh Sharma, ${ }^{1}$ Jenny Laurila, ${ }^{1}$ Prodeep Paudel, ${ }^{1}$ Ilkka Miinalainen, ${ }^{2}$ \\ Veli-Pekka Ronkainen, ${ }^{2}$ Reetta Hinttala, ${ }^{2,3}$ Kid Törnquist, ${ }^{4,5}$ Peppi Koivunen, ${ }^{1}$ and \\ DJohanna Myllyharju' ${ }^{1}$
}

https://doi.org/10.1523/ENEURO.0253-20.2020

${ }^{1}$ Oulu Center for Cell-Matrix Research, Biocenter Oulu and Faculty of Biochemistry and Molecular Medicine, University of Oulu, Oulu 90014, Finland, ${ }^{2}$ Biocenter Oulu, University of Oulu, Oulu 90014, Finland, ${ }^{3}$ PEDEGO Research Unit, Faculty of Medicine, University of Oulu, Oulu 90014, Finland, ${ }^{4}$ Cell Biology, Faculty of Science and Engineering, Åbo Akademi University, Turku 20500, Finland, and ${ }^{5}$ Minerva Foundation Institute for Medical Research, Biomedicum Helsinki, Helsinki 00290, Finland

\begin{abstract}
Prolyl 4-hydroxylases (P4Hs) have vital roles in regulating collagen synthesis and hypoxia response. A transmembrane $\mathrm{P} 4 \mathrm{H}$ ( $\mathrm{P} 4 \mathrm{H}-\mathrm{TM}$ ) is a recently identified member of the family. Biallelic loss of function $\mathrm{P} 4 \mathrm{H}-\mathrm{TM}$ mutations cause a severe autosomal recessive intellectual disability syndrome in humans, but functions of $\mathrm{P} 4 \mathrm{H}-\mathrm{TM}$ are essentially unknown at cellular level. Our microarray data on $P 4 h-\mathrm{tm}^{-1-}$ mouse cortexes where $\mathrm{P} 4 \mathrm{H}-\mathrm{TM}$ is abundantly expressed indicated expression changes in genes involved in calcium signaling and expression of several calcium sequestering ATPases was upregulated in $\mathrm{P} 4 \mathrm{~h}-\mathrm{tm}^{-1-}$ primary mouse astrocytes. Cytosolic and intraorganellar calcium imaging of $P 4 h-\mathrm{tm}^{-/-}$cells revealed that receptor-operated calcium entry (ROCE) and store-operated calcium entry (SOCE) and calcium re-uptake by mitochondria were compromised. HIF1, but not HIF2, was found to be a key mediator of the P4H-TM effect on calcium signaling. Furthermore, total internal reflection fluorescence (TIRF) imaging showed that calcium agonist-induced gliotransmission was attenuated in P4h-tm ${ }^{-1-}$ astrocytes. This phenotype was accompanied by redistribution of mitochondria from distal processes to central parts of the cell body and decreased intracellular ATP content. Our data show that $\mathrm{P} 4 \mathrm{H}-\mathrm{TM}$ is a novel regulator of calcium dynamics and gliotransmission.
\end{abstract}

Key words: calcium signaling; hypoxia-inducible factor; prolyl 4-hydroxylase; vesicular exocytosis

\section{Significance Statement}

Transmembrane prolyl 4-hydroxylase ( $\mathrm{P} 4 \mathrm{H}-\mathrm{TM})$ is a recently identified member of the $\mathrm{P} 4 \mathrm{H}$ family. Biallelic loss of function $\mathrm{P} 4 \mathrm{H}-\mathrm{TM}$ mutations cause a syndromic form of severe cognitive impairment in humans. Here, we demonstrate for the first time that inactivation of $\mathrm{P} 4 \mathrm{H}-\mathrm{TM}$ in astrocytes disturbs calcium signaling in a HIF1-dependent manner. The observed changes in calcium signaling were accompanied by attenuated vesicular exocytosis. These findings suggest that abnormal calcium signaling resulting from $\mathrm{P} 4 \mathrm{H}-\mathrm{TM}$ inactivation may be involved in the molecular basis of a severe human intellectual disability syndrome. Therefore, future studies to unravel the exact molecular mechanisms how P4H-TM affects calcium signaling and what effects $\mathrm{P} 4 \mathrm{H}-\mathrm{TM}$ has on astrocyte functions in healthy and various disease conditions will be of interest.

Received June 12, 2020; accepted November 27, 2020; First published December 8, 2020.

J.M. owns equity in FibroGen Inc., which develops HIF-P4H inhibitors as potential therapeutics. This company supports research in the J.M. group. All other authors declare no competing financial interests.
Author contributions: N.B., I.M., V.-P.R., R.H., K.T., P.K., and J.M. designed research; N.B., S.S., J.L., P.P., I.M., and V.-P.R. performed research; N.B., S.S., J.L., P.P., I.M., V.-P.R., R.H., K.T., P.K., and J.M. analyzed data; N.B. and J.M. wrote the paper. 


\section{Introduction}

The prolyl 4-hydroxylase ( $\mathrm{P} 4 \mathrm{H})$ family of enzymes includes the collagen $\mathrm{P} 4 \mathrm{Hs}$ and hypoxia-inducible factor (HIF) P4Hs that have vital roles in collagen synthesis and in the regulation of the hypoxia response, respectively (Myllyharju, 2008, 2013; Ratcliffe, 2013; Ivan and Kaelin, 2017). HIFs (HIF1, HIF2, and HIF3) are heterodimeric transcription factors consisting of an oxygen-sensitive $\alpha$-subunit and a constitutive $\beta$-subunit. HIF-P4Hs hydroxylate two prolyl residues located in the oxygen-dependent degradation domain (ODDD) of the HIF $\alpha$ subunit in normoxia. Hydroxylation leads to von Hippel-Lindau (VHL)-targeted degradation of HIF $\alpha$, which suppresses the transcription of hypoxia responsive genes in normoxia. In contrast, HIF-P4Hs are inactivated in hypoxia, which leads to stabilization and accumulation of HIF and induction of hypoxia responsive genes. Originally three members of the HIF$\mathrm{P} 4 \mathrm{H}$ family were identified: HIF-P4H-1, HIF-P4H-2, and HIF-P4H-3 (also known as PHD1, PHD2, and PHD3 or EGLN2, EGLN1, and EGLN3; Myllyharju, 2013; Ratcliffe, 2013; Ivan and Kaelin, 2017).

Our laboratory was among the first to clone and characterize a human transmembrane $\mathrm{P} 4 \mathrm{H}$ (P4H-TM), a distinct member of the $\mathrm{P} 4 \mathrm{H}$ family (Oehme et al., 2002; Koivunen et al., 2007). P4H-TM contains a transmembrane domain toward its $\mathrm{N}$ terminus and we showed that it is located in the endoplasmic reticulum (ER) membranes with its catalytic site inside the lumen (Koivunen et al., 2007). The cellular location suggested that $\mathrm{P} 4 \mathrm{H}-\mathrm{TM}$ could be a collagen $\mathrm{P} 4 \mathrm{H}$ and the $\mathrm{P} 4 \mathrm{H}-\mathrm{TM}$ amino acid sequence also resembled more closely those of the collagen $\mathrm{P} 4 \mathrm{Hs}$ than the HIF-P4Hs (Koivunen et al., 2007). However, P4H-TM lacked the peptide-substrate-binding domain of the collagen P4Hs (Myllyharju and Kivirikko, 1999), and it did not hydroxylate collagen polypeptides in vitro (Koivunen et al., 2007). Instead, like HIF-P4Hs, P4H-TM has been shown to regulate the oxygen-dependent stability of $\mathrm{HIF} \alpha$ in cellulo and to hydroxylate the HIF $\alpha$ ODDD in vitro (Koivunen et al., 2007). However, P4H-TM did not show as strict target proline specificity in the hydroxylation of the HIF $\alpha$ ODDD as the HIF-P4Hs (Koivunen et al., 2007). Analyses of P4h-tm ${ }^{-1-}$ mice have shown that $\mathrm{P} 4 \mathrm{H}-\mathrm{TM}$ affects erythropoiesis (Laitala et al., 2012), tumor angiogenesis (Klotzsche-von Ameln et al.,

This work was supported by Academy of Finland Project Grants 296498 (to J.M.) and 266719 and 308009 (to P.K.), the Academy of Finland Center of Excellence 2012-2017 Grant 251314 (to J.M.), the S. Jusélius Foundation (J.M., P.K.), the Jane and Aatos Erkko Foundation (J.M., P.K.), and FibroGen Inc. (J.M.).

Acknowledgements: We thank Prof. Dr. Axel Methner (Johannes Gutenberg University) for his kind advice on the special features of CEPIA plasmids; Raija Salmu, the Biocenter Oulu core facilities, for Transgenic Animals and Light and electron microscopy (cofunded by the University of Oulu and Biocenter Finland); and Laboratory Animal Center of University of Oulu for their excellent technical assistance; and Prof. Gero Miesenböck for providing us Syb2pHluorin plasmid.

Correspondence should be addressed to Johanna Myllyharju at johanna. myllyharju@oulu.fi.

https://doi.org/10.1523/ENEURO.0253-20.2020

Copyright (C) 2021 Byts et al.

This is an open-access article distributed under the terms of the Creative Commons Attribution 4.0 International license, which permits unrestricted use, distribution and reproduction in any medium provided that the original work is properly attributed.
2013), renal and retinal development (Leinonen et al., 2016) and behavior (Leinonen et al., 2019) in mouse, and that some of these phenotypic abnormalities are not likely to be HIF-mediated. Therefore, it has been suggested that $\mathrm{P} 4 \mathrm{H}-\mathrm{TM}$ may have additional, yet uncharacterized substrates (Koivunen et al., 2007; Leinonen et al., 2016, 2019).

$\mathrm{P} 4 \mathrm{H}-\mathrm{TM}$ was shown to be highly expressed in the brain in comparison to other tissues (Koivunen et al., 2007; Leinonen et al., 2016), nevertheless its function in the brain is unknown. The cellular functions of $\mathrm{P} 4 \mathrm{H}-\mathrm{TM}$ in brain cells are of considerable interest because loss-offunction $\mathrm{P} 4 \mathrm{H}-\mathrm{TM}$ mutations have been shown to cause a human HIDEA syndrome characterized by hypotonia, intellectual disability, and eye abnormalities (Kaasinen et al., 2014; Rahikkala et al., 2019). Therefore, in the current study we sought to reveal cellular functions and pathways controlled by $\mathrm{P} 4 \mathrm{H}-\mathrm{TM}$ in brain cells, which potentially could affect brain function.

Taking into consideration the important secretory role of astrocytes in the brain and their ability to signal to neurons and neighbor astrocytes through the vesicular release of neuroactive and glia active substances (gliotransmission) in a calcium-dependent manner (Bezzi and Volterra, 2001; Oliet et al., 2001; Lalo et al., 2014; Vardjan and Zorec, 2015), we chose astrocytes as a cellular system. We investigated the effects of the lack of $\mathrm{P} 4 \mathrm{H}-\mathrm{TM}$ on calcium dynamics and vesicular exocytosis by imaging live cortical astrocytes from wild-type (WT) and $\mathrm{P} 4 \mathrm{H}-\mathrm{TM}$ knock-out (KO) mice and demonstrated the importance of $\mathrm{P} 4 \mathrm{H}-\mathrm{TM}$ for both processes. Our data also show that HIF1 is the key mediator of this $\mathrm{P} 4 \mathrm{H}-\mathrm{TM}$ function.

\section{Materials and Methods}

\section{Animals and ethics approval}

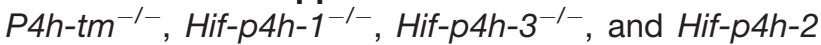
hypomorph mice (Hyvärinen et al., 2010; Laitala et al., 2012; Ullah et al., 2017) and their corresponding WT controls were used for cortical dissection and isolation of primary astrocytes. In the hypomorph Hif-p4h-2 mouse line (full $\mathrm{KO}$ of this gene is embryonic lethal) the Hif-p4h-2 gene is disrupted by a GeneTrap (gt) insertion cassette, but because of partial skipping of the insertion cassette varying amounts of WT Hif-p4h-2 mRNA is generated from the gene-trapped alleles in different tissues (Hyvärinen et al., 2010). Animal experiments were approved by the Animal Experiment Board of Finland, following the regulations of the EU Directive 86/609/EEC, the European Convention ETS123, and the national legislation of Finland. The recommendations given by the Federation of European Laboratory Animal Science Associations and the Finnish and EU legislations concerning laboratory animal experiments and handling were followed.

\section{Microarray}

The GeneChip experimental procedures were performed according to the Affymetrix GeneChip Expression Analysis Technical Manual. Shortly, total RNA was extracted from 
cortical tissue using TriPure isolation reagent (Roche Applied Science). Double-stranded DNA was synthesized using $8 \mu \mathrm{g}$ of total RNA as a template by means of the One-cycle cDNA synthesis kit (Affymetrix) and T7(dT)24 primer, and the DNA was purified using the GeneChip Sample Cleanup Module (QIAGEN). In vitro transcription was performed to produce biotin-labeled cRNA using an IVT labeling kit (Affymetrix) according to the manufacturer's instructions. Biotinylated cRNA was cleaned with a GeneChip Sample Cleanup Module (QIAGEN), fragmented to 35-200 nt, and hybridized to Affymetrix Mouse Genome 430_ 2.0 arrays, which contain $\sim 45,000$ mouse transcripts. After washing, the array was stained with streptavidin-phycoerythrin (Invitrogen), and the staining signal was amplified with biotinylated anti-streptavidin (Vector Laboratories) and a second staining with streptavidin-phycoerythrin and then scanned on a GeneChip Scanner 3000. Hybridization signal intensities were quantified using Affymetrix GeneChip Operating System (Affymetrix). CEL files and the probe annotation files were downloaded, and the gene expression data of all samples were normalized using the GenePattern software (freely available software package developed at the Broad Institute of MIT and Harvard (http://genepattern. broadinstitute.org; Reich et al., 2006). Normalized expression ratio data were further analyzed using the Gene Set Enrichment Analysis (GSEA) to identify significantly enriched groups of genes. Kyoto Encyclopedia of Genes and Genomes (KEGG) database and Reactome Knowledgebase was used for analysis and expression values between WT and $\mathrm{P} 4 \mathrm{H}-\mathrm{TM} \mathrm{KO}$ cortexes were compared. Gene datasets were considered to be significantly enriched according to GSEA default settings, $p<0.05$.

\section{Data availability}

The microarray data have been deposited in the NCBI Gene Expression Omnibus (GEO; Edgar et al., 2002) and are accessible through GEO Series accession number GSE126425.

\section{Primary cortical astrocytes}

Primary cortical astrocyte cultures were prepared as described (McCarthy and de Vellis, 1980) from 1- to 2-dold P4h-tm ${ }^{-1-}$, Hif-p4h-1 $1^{-1-}$, Hif-p4h-2 hypomorph, and Hif-p $4 h-3^{-1-}$ mice and their WT controls. The pups were taken for cell culture isolation regardless of their gender. The mice were killed via decapitation, and cortexes were removed of the meninges, dissected and trypsinized. After mechanical trituration, the cell suspension was passed through a $40-\mu \mathrm{m}$ cell strainer and plated on polyD-lysine-coated dishes in a density of $25,000 \mathrm{cells} / \mathrm{cm}^{2}$ in DMEM (Lonza) containing $1 \mathrm{~g} / \mathrm{l}$ glucose and supplemented with $1 \%$ penicillin/streptomycin and $20 \%$ fetal calf serum (FCS). Cultures were established from cells pooled from one to four animals of the same genotype. The cultures were grown at $37^{\circ} \mathrm{C}$ under $5 \% \mathrm{CO}_{2} / 95 \%$ air and $90 \%$ humidity in $10 \%$ FCS-containing medium, with medium being exchanged every second day. After 9$10 \mathrm{~d}$, the cells were trypsinized and passaged. The cells were used from the first or second passage (two to three weeks in culture) for the experiments. Enrichment for astroglial cells was $\sim 90 \%$ under these culture conditions, microglia content was $\sim 4 \%$ and neuronal content $\sim 2 \%$ as detected by immunocytochemistry for GFAP, CD11b, and $\beta$-Tubulin III cell-type markers, respectively (data not shown). The cells were treated with ATP (Sigma), thapsigargin (TG; BioVision), 2-aminoethoxydiphenyl borate (2-APB; Tocris), ionomycin (BioVision), puromycin (Sigma), anisomycin (Sigma), and EGTA (Sigma). The treatment times and doses used are described in the figure legends of the respective experiments.

\section{Oxygen-glucose deprivation (OGD) treatment}

In OGD treatment, medium was changed to DMEM containing no glucose (ThermoFisher) and supplemented with $1 \%$ penicillin/streptomycin and 10\% FCS and the cells were grown at $37^{\circ} \mathrm{C}$ under $5 \% \quad \mathrm{CO}_{2} / 1 \% \mathrm{O}_{2}$ for the periods of time indicated in the figure legends.

\section{qRT-PCR}

Total RNA was isolated using TriPure isolation reagent (Roche Applied Science) and further purified with an EZNA total RNA kit (Omega Biotek), and reverse transcription was performed with an iScript cDNA synthesis kit (Bio-Rad Laboratories). qRT-PCR was performed with iTaq Universal SYBR Green Supermix (Bio-Rad Laboratories) and a CFX96 Touch real-time PCR detection system, using primer sets listed in Table 1.

\section{Western blot analysis}

To prepare protein samples from primary cortical astrocytes for Western blot analysis, the cells were scraped in lysis buffer (50 mM Tris- $\mathrm{HCl}, \mathrm{pH} 8.0,50 \mathrm{~mm} \mathrm{NaCl}, 1 \%$ Triton X-100, and $1 \mathrm{~mm}$ dithiothreitol) supplemented with protease and phosphatase inhibitor cocktails (Roche) at $4^{\circ} \mathrm{C}$. The samples were homogenized via mechanical trituration through a 27-G needle, and the lysates were subjected to SDS-PAGE analysis. The protein concentration of the samples was determined using a Bio-Rad protein assay dye reagent concentrate (Bio-Rad Laboratories) or NanoDrop 2000 spectrophotometer (ThermoScientific). For detection of small molecular weight proteins, such as SEC61B and SEC61G subunits, the samples were loaded on 10-20\% Mini-Protean Tris-Tricine Gels (Bio-Rad Laboratories), while for detection of higher molecular weight proteins, such as HIF1 $\alpha$, SERCA2 and PMCA3, the samples were loaded on $8 \%$ Tris-glycine SDS-PAGE gels. Otherwise, $10 \%$ SDS-PAGE gels were used. Proteins were transferred onto nitrocellulose or PVDF membranes using standard methods. The blots were probed with antibodies recognizing ATP2A2/SERCA2 (Cell Signaling, D51B11), ATP2A3/SERCA3 (Boster Biological Technology, RP1055), PMCA2 (ATP2B2, St John's Laboratory, STJ28955), PMCA3 (G-6; Santa Cruz, sc-390148), SEC61A (Abcam, ab183046), SEC61B (Protein Tech, 15 087-I-AP), SEC61G (Protein Tech, 11147-2-AP), phospho-elF2 $\alpha$ pSer51 (Thermo Scientific, MA5-15133), elF2 $\alpha$ (Invitrogen, AHO1182), diphosphorylated Erk1/2 (Sigma- 
Table 1: Sequences of the qRT-PCR primers

\begin{tabular}{lll}
\hline Gene & Forward primer & Reverse primer \\
\hline P4H-TM & AGCCAGTGCCAACCTTG & AGAGGGAAATCGTGCGTGAC \\
$\beta$-Actin & CAATAGTGATGACCTGGCCGT & CTGGGAATCTTCGATCCGGA \\
PMCA2 & AGAGATAGACCACGCAGAGC & CACCAGACACATTCCCACAG \\
PMCA3 & GCAGGACGTGACTCTCATCA & ATCTGCAGGGTTCCCAGATA \\
PMCA4 & CTTAATGGACCTGCGAAAGC & TGGTGGGTAGTCATGGTCTG \\
Orai1 & TTACTCCGAGGTGATGAGCC & CAAACAGATGCACGGCTACC \\
Orai2 & AGCTACCTGGAACTCGTCAC & GCTTGGAAGGCTGTTGTGA \\
Orai3 & CCAACGACTGCACAGATACG & CACCTCATCCACAGTCCAGT \\
STIM1 & ACGATGCCAATGGTGATGTG & GGCAACTTGACACAGACAGG \\
STIM2 & CAATCGTGCCACAGTTCCA & GGAAGTCAGCCAGGACAGAG \\
SEC61A & GCTCCTGTGCATTCTTCTCC & TTCTCTGCCGAACAGTGGAT \\
SEC61B & CCGTTCTTAGGCATCAGCAT & TAACCAGCCGAATTGAGTCC \\
SEC61G & CGGTTCTCTCCTGAGCTACG & TTCGGGCCACAAACTTGAG \\
SERCA2A & CAGAGCACAGATGGTGGCTA \\
SERCA2B & CTGTCATCTGCTTGTCCATG & TCCAATCCCTCAGACACACA \\
SERCA3 & CCACTCTCCTGCATCTCCTC & CTTGTAATGGGTCTCTCAGTCTCTT \\
SPCA1 & Quantitect primer asSays (QIAGEN: QT00166278, QT01542072, QT01542079) \\
MCU & CGCCAGGAATATGTTATCCA & GGTGGCAAAATATCGGAAAA \\
MICU1 & GAACTAGCTGTGGGCTCTCG & CCAGCATCTTCTTCTCGTTCA \\
MCUR1 & AGCCCTCAGAGCAGAAAATG & AAGTGGCAACTGATGAGCAA \\
HIF1 $\alpha$ & GGCGAGAACGAGAAGAAAAA & \\
\hline
\end{tabular}

Aldrich, M8159), Erk1/2 (Sigma-Aldrich, M5670), phosphop38 MAPK (Cell Signaling Technology, 4511S), p38 MAPK (Cell Signaling Technology, 9212S), NDUFS3 (Abcam, ab14711), ATP5A (Abcam, ab14748), UQCRC2 (Abcam, ab14745), COX I (Molecular Probes, A6403), SDHA (Abcam, ab14715), HIF1 $\alpha$ (Abcam, ab2185), HIF2 $\alpha$ (Abcam, ab199), GFP (Abcam, ab13970), or synaptobrevin 2 (Syb2; Vamp2, Abcam, ab3347). Staining for $\beta$-actin (Novus Biologicals, NB600-501) was used as a control for protein loading. The blots were quantified using Fiji-ImageJ software (a Java-based public domain software). The densitometry data were normalized to $\beta$-actin.

\section{Live cell imaging of cellular calcium dynamics}

Astrocytes were grown on cell culture dishes with a glass bottom (Greiner; 65,000 cells $/ \mathrm{cm}^{2}$ ). The cells were loaded with Fluo-4 A.M. (4 $\mu \mathrm{M}$, Invitrogen) for $20 \mathrm{~min}$ and then incubated for a further $30 \mathrm{~min}$ in $37^{\circ} \mathrm{C}$ before measurement. Imaging was performed in normal extracellular solution (NES) containing $136 \mathrm{~mm} \mathrm{NaCl}, 2.5 \mathrm{~mm} \mathrm{KCl,} 10$ mM HEPES, $1.3 \mathrm{~mm} \mathrm{MgCl}_{2}, 10 \mathrm{~mm}$ glucose, and $2 \mathrm{~mm}$ $\mathrm{CaCl}_{2}, \mathrm{pH} 7.3$ (Royle et al., 2008) as described previously (Terunuma et al., 2015). In some experiments, extracellular calcium was chelated with 2 mм EGTA added into the buffer. Fluorescence images were acquired with a Zeiss Cell Observer Spinning Disk Confocal microscope using epifluorescence illumination (excitation filter bandpass $470 / 20 \mathrm{~nm}$, emission 525/50 nm), LD LCl Plan-Apochromat $25 \times / 0.8 \mathrm{~W}$ objective, Zen 2012 Blue software (Carl Zeiss) and Hamamatsu ORCA-R2 camera (Hamamatsu). Images were captured at 1-s intervals for up to $2 \mathrm{~min}$ (in some experiments up to $4 \mathrm{~min}$ ) in $37^{\circ} \mathrm{C}$ and $5 \% \mathrm{CO}_{2}$. Image data were analyzed by Zen 2012 Blue software and subsequently by OriginPro 2016 software (OriginLab). The change in intracellular free calcium concentration $\left(\left[\mathrm{Ca}^{2+}\right]_{\mathrm{i}}\right)$ is represented by relative fluorescence intensity $\left[\left(F_{1}-F_{0}\right) / F_{0}\right.$, relative unit (r.u.)] ( $F_{0}$, at rest; $F_{1}$, after administration of drugs, background subtracted) in the selected cytoplasmic or nuclear parts of the cells.

\section{Intraorganellar calcium imaging}

Astrocytes were grown on cell culture dishes with a glass bottom (Greiner; 65,000 cells $/ \mathrm{cm}^{2}$ ). To assess ER $\mathrm{Ca}^{2+}$ concentration $\left(\left[\mathrm{Ca}^{2+}\right]_{\mathrm{er}}\right)$ and mitochondrial $\mathrm{Ca}^{2+}$ concentration $\left(\left[\mathrm{Ca}^{2+}\right]_{\mathrm{m}}\right)$, the astrocytes were co-transfected with the plasmids pCMV R-CEPIA1er and pCMV CEPIA2mt using Lipofectamine 2000 (Invitrogen) as described (Rao et al., 2015). These plasmids are calciummeasuring organelle-entrapped protein indicators and were a gift from Masamitsu lino (Addgene plasmids \#58216 and \#58218, respectively; Suzuki et al., 2014). Imaging was performed in NES solution $24 \mathrm{~h}$ after transfection. Fluorescence images were acquired with Zeiss Cell Observer Spinning Disk Confocal microscope, LD LCI Plan-Apochromat 25×/0.8W objective, Zen 2012 Blue software and Hamamatsu ImagEM EM-CCD camera. Images were captured at 1-s intervals for up to $2 \mathrm{~min}$ in $37^{\circ} \mathrm{C}$ and $5 \% \mathrm{CO}_{2}$. The following excitation/emission wavelengths were used: pCMV CEPIA2mt (excitation $488 \mathrm{~nm}$, emission 525/50 nm) and pCMV R-CEPIA1er (excitation $561 \mathrm{~nm}$, emission 629/62 nm). Ca ${ }^{2+}$-insensitive fluorescence was subtracted from each wavelength before calculations to normalize fluorescence values. The values were then plotted against time and shown as $F_{1} / F_{0}\left(F_{0}\right.$, at rest; $F_{1}$, after administration of ATP, background subtracted). The peak fluorescence and peak time were measured for each plot. The change in intraorganellar free calcium concentration $\left(\left[\mathrm{Ca}^{2+}\right]_{\mathrm{er}}\right.$ and $\left.\left[\mathrm{Ca}^{2+}\right]_{\mathrm{m}}\right)$ was assessed for each individual cell as peak fluorescence from the corresponding plot ([1- $F_{1} / F_{0}$, r.u. $]$, and $\left[F_{1} / F_{0}-1\right.$, r.u.], respectively). 


\section{HIF1 $\alpha$ and HIF2 $\alpha$ SiRNA transfection}

The sequences of siRNA targeting mouse HIF1 $\alpha$ and HIF2 $\alpha$ were predesigned by Sigma (RNAi ID: SASI_ Mm01_00070476 and SASI_Mm01_00070480 for HIF1 $\alpha$, SASI_Mm01_00144144 and SASI_Mm02_00317873 for HIF2 $\alpha$ ). Cyanine 5 fluorescent group was added to $5^{\prime}$ end of the sense strand. MISSION siRNA Fluorescent Universal Negative Control \#1, Cyanine 5 (SIC005, Sigma) was used as a negative control. Astrocytes were transfected with the siRNA using X-tremeGENE siRNA Transfection reagent (Sigma) according to the manufacturer's instructions. After treatment with siRNA, the cells were incubated at $37^{\circ} \mathrm{C}$ with $5 \% \mathrm{CO}_{2} / 95 \%$ air for further $24 \mathrm{~h}$. At this time point, the majority of cells were Cyanine 5 positive.

\section{Total internal reflection fluorescence (TIRF) microscopy}

Vesicular exocytosis in primary astrocytes was studied by an optical method (Miesenböck et al., 1998; Sankaranarayanan et al., 2000) by imaging of a superecliptic Syb2-pHluorin. The Syb2-pHluorin plasmid was kindly provided by Prof. Gero Miesenböck. Astrocytes plated on cell culture dishes with a glass bottom 65,000 cells $/ \mathrm{cm}^{2}$ ) were transfected with the Syb2-pHluorin plasmid using Lipofectamine 2000 (Invitrogen), and 24 h later, time-lapse TIRF imaging was performed. During imaging cells were incubated in an environmental control system set to $37^{\circ} \mathrm{C}$ and $5 \% \mathrm{CO}_{2}$ in the NES-buffer. Zeiss Cell Observer Spinning Disk Confocal microscope equipped with Laser TIRF3 module and alpha Plan-Apochromat $63 \times / 1.46$ objective (Carl Zeiss) was used for TIRF imaging in combination with Hamamatsu ORCA-R2 camera (Hamamatsu) controlled by Zen 2012 Blue software. Excitation laser wavelength was $488 \mathrm{~nm}$, and images were acquired through a $525 / 31-n m$ bandpass filter at the rate of one image per second. When focusing on the cell, multiple fusion/release events of Syb2-pHluorin-positive vesicles over time were observed as a sudden appearance of spot-like fluorescent signal in evanescent field followed by diffusion of signal in the vicinity. We quantified automatically the number of Syb2-pHluorin fluorescent spots by thresholding the signals that were significantly brighter than the cellular background per time frame in TIRF movies. Analysis of TIRF movies was performed using Zen 2012 Blue software and particle analyzer algorithm implemented as a plugin in Fiji (Schindelin et al., 2012). Data are presented as the number of exocytotic events per $\mu \mathrm{m}^{2}$ of cellular surface over time, typically $2 \mathrm{~min}$. When indicated, data are normalized by resting levels, and are presented as ratio between the number of evoked exocytotic events per $\mu \mathrm{m}^{2}$ and the number of baseline exocytotic events per $\mu \mathrm{m}^{2}$ over time. For statistical analysis of both the raw and normalized data, the area under the curve was counted using the GraphPad Prizm software.

\section{Quantification of intracellular ATP level}

Whole-cell lysates from cultured primary cortical astrocytes were prepared in a $50 \mathrm{~mm}$ Tris- $\mathrm{HCl}, \mathrm{pH} 8.0,50 \mathrm{~mm}$ $\mathrm{NaCl}, 1 \%$ Triton $\mathrm{X}-100$, and $1 \mathrm{~mm}$ dithiothreitol lysis buffer supplemented with protease inhibitor cocktail (Roche).
The ATP amount was quantified in aliquots of $2.5 \mu \mathrm{g}$ of protein using ATP determination kit (Invitrogen) according to the manufacturer's instructions. Luminescence was measured using Infinite M1000 Pro multi-mode microplate reader (Tecan) and ATP concentrations were calculated according to the manufacturer's instructions. ATP standard curves were established in each experiment.

\section{Determination of ATPase activity}

Whole-cell lysates were prepared from the primary cortical astrocytes as described above for the ATP quantification. Contamination with inorganic phosphate $(\mathrm{Pi})$ was removed via incubation of the lysate with $\mathrm{Pi}$ Bind resin (Innova Biosciences) for $2 \mathrm{~h}$ at $+4^{\circ} \mathrm{C}$. ATPase activity was quantified in aliquots of $10 \mu \mathrm{g}$ of protein using ATPase assay kit (Innova Biosciences) according to the manufacturer's instructions. The amount of Pi released was quantified colorimetrically at $630 \mathrm{~nm}$ using Infinite M1000 Pro multi-mode microplate reader (Tecan). Pi standard curve was established in each experiment.

\section{Monitoring of intracellular oxygen content}

Intracellular oxygen was assessed using the oxygensensitive probe MitoXpress-Intra (LuxelBiosciences). The measurement is based on the ability of $\mathrm{O}_{2}$ to quench the emission of the probe, which is taken by endocytosis. Cultured primary cortical astrocytes at full confluence were loaded with MitoXpress-Intra $(10 \mu \mathrm{g} / \mathrm{ml})$ and incubated for further $20 \mathrm{~h}$ either in normoxic or OGD conditions. Intracellular $\mathrm{O}_{2}$ was then measured using the time-resolved fluorescence mode of the FLUOstar Omega microplate reader (BMG Labtech) according to manufacturer's instructions, with excitation performed at $340 \mathrm{~nm}$ and emission collected at $655 \mathrm{~nm}$. Phosphorescent intensities were measured at delay times of 30 and $70 \mathrm{~ms}$. The ratio of these intensities was subsequently converted into oxygen content in cellular monolayer using the plate reader software MARS with predefined templates.

\section{Analysis of mitochondrial membrane potential}

Mitochondrial membrane potential was measured based on the accumulation of tetramethylrhodamine methyl ester (TMRM) fluorescence using FLUOstar Omega microplate reader and the Mitochondrial Membrane Potential Assay kit (Cell Signaling) according to the manufacturer's instructions. TMRM is a cell membrane permeable cationic dye, which accumulates electrophoretically into mitochondria in response to the negative mitochondrial $\Delta \psi$ (Ehrenberg et al., 1988). Primary cortical astrocytes were loaded with 150 nм TMRM (Sigma) for $5 \mathrm{~min}$ in an assay buffer containing $80 \mathrm{~mm} \mathrm{NaCl}, 75 \mathrm{~mm} \mathrm{KCl}, 25 \mathrm{~mm}$ D-glucose, and $25 \mathrm{~mm}$ HEPES, pH 7.4. Fluorescence was measured on the plate reader at excitation $544 \mathrm{~nm}$ and emission $590 \mathrm{~nm}$. In order to control for plasma membrane potential variations, each assay was performed in parallel as above with a 15-min preincubation with $10 \mu \mathrm{m}$ carbonyl cyanide 3-chlorophenylhydrazone (CCCP; Sigma). All data were expressed as the total TMRM fluorescence minus the CCCP treated TMRM fluorescence. 


\section{Blue native (BN) electrophoresis}

Mitochondrial protein complex samples for BN-PAGE were prepared from cultured primary cortical astrocytes as previously described (Nijtmans et al., 2002). Digitonin $(2 \mathrm{mg} / \mathrm{ml})$-treated cell pellets were solubilized in $1.5 \mathrm{~m}$ aminocaproic acid, $50 \mathrm{~mm}$ Bis-Tris- $\mathrm{HCl}, \mathrm{pH} 7.0$, and $1 \%$ dodecylmaltoside. The samples were incubated on ice for $15 \mathrm{~min}$ and centrifuged at $20,000 \times g$ for $20 \mathrm{~min}$ to remove insolubilized material. Supernatants containing the mitochondrial protein complexes were collected. BN-PAGE electrophoresis and blotting were performed as previously described (Ugalde et al., 2004). Briefly, 20- $\mu$ g samples were combined with $5 \%$ Serva blue $G$ and separated on $5-15 \%$ gradient acrylamide gel. The proteins were transferred to a nitrocellulose membrane by semi-dry protein transfer. Western blotting was performed using antibodies against NDUFS3 (Abcam, ab14711), ATP5A (Abcam, ab14748), UQCRC2 (Abcam, ab14745), COX I (Molecular probes, A6403), and SDHA (Abcam, ab14715).

\section{Transmission electron microscopy (TEM)}

TEM was conducted as previously described (Konzack et al., 2015). The primary cortical astrocytes were fixed in $1 \%$ glutaraldehyde and $4 \%$ formaldehyde mixture in $0.1 \mathrm{~m}$ phosphate buffer for $10 \mathrm{~min}$. The cells were detached, and fixation was continued for $1 \mathrm{~h}$. After fixation, the cells were centrifuged, immersed in $2 \%$ agarose in distilled water, postfixed in $1 \%$ osmium tetroxide, dehydrated in acetone, and embedded in Epon LX 112 (Ladd Research Industries). Thin sections were cut with a Leica Ultracut UCT ultramicrotome, stained in uranyl acetate and lead citrate, and examined in a Tecnai G2 Spirit TEM (FEI Europe). Images were captured by using a Quemesa CCD camera (Olympus Soft Imaging Solutions $\mathrm{GmbH}$ ) and analyzed with a Tecnai G2 Spirit 120 kV TEM with Veleta and Quemesa CCD cameras and a Philips CM100 equipped with CCD camera 23.

\section{Mitochondrial morphometry}

TEM images were analyzed using iTEM software. Mitochondrial morphologic characteristics including the number of mitochondria per square area of the cell, area of individual mitochondrion, length or aspect ratio (the ratio between the major and minor axes of the ellipse equivalent to the mitochondrion), degree of branching or form factor [defined as $\left(\mathrm{P}_{\mathrm{m}}{ }^{2}\right) /\left(4 \pi \mathrm{A}_{\mathrm{m}}\right)$, where $\mathrm{P}_{\mathrm{m}}$ is the length of mitochondrial outline and $\mathrm{Am}$ is the area of mitochondrion] were quantified as previously described (Mortiboys et al., 2008). In addition, the number of electron-lucent (clear) coated and uncoated vesicular structures per square area of the cell, as well as average area of these vesicles were quantified.

\section{Immunostaining for Tom20}

Primary cortical astrocytes grown on poly-D-lysinecoated coverslips were fixed with $20 \%$ methanol for $7 \mathrm{~min}$ and permeabilized with $0.1 \%$ Triton X-100/PBS for $15 \mathrm{~min}$. The cells were then incubated in $5 \%$ bovine serum albumin (BSA)/PBS blocking solution for $30 \mathrm{~min}$ and subsequently incubated with a Tom20 antibody (Cell Signaling, 42406S) diluted in blocking solution overnight at $+4^{\circ} \mathrm{C}$. After washing, the fluorescent Cy3-conjugated secondary antibody (Jackson ImmunoResearch) were diluted in 1\% BSA/PBS and applied for $1 \mathrm{~h}$ at room temperature. Immunofluorescence data were obtained using Zeiss Axio Scope.A1 fluorescence microscope with a Zeiss AxioCam MRm Camera (Carl Zeiss) equipped with Zen 2011 Blue software. To estimate mitochondria distribution in the cells the number of cells with clear mitochondrial staining in distal processes (phenotype 1) and the number of cells with distal processes virtually devoid of any staining (phenotype 2) were quantified as percent to the total number of cells.

\section{Experimental design and statistical analysis}

Experimental design and details on the number of animals and samples used in each individual experiment are specified in the figure legends. Data, expressed as mean \pm SEM, were analyzed using the GraphPad Prism statistical analysis software. The data were checked for Gaussian distribution using the D'Agostino-Pearson omnibus normality test or Shapiro-Wilk normality test. In case of comparison between two groups, unpaired twotailed Student's $t$ test was performed. When comparisons were done between three or more groups, the data were analyzed using one-way ANOVA test with subsequent post hoc tests. Values of $p<0.05$ were considered statistically significant.

\section{Results}

\section{Expression of several genes involved in calcium signaling, in particular certain calcium sequestering ATPases, is altered in P4H-TM KO mice}

We have recently shown high abundance of $\mathrm{P} 4 \mathrm{H}-\mathrm{TM}$ expression in the cortex, amygdala, hippocampus and hypothalamus in adult mice (Leinonen et al., 2016). To study the functional role of $\mathrm{P} 4 \mathrm{H}-\mathrm{TM}$ in the brain, we first performed microarray experiments of cortical tissue isolated from WT and P4H-TM KO (P4h-tm $\left.{ }^{-1-}\right)$ mice. Comparison of the expression data by GSEA software revealed significant changes in calcium signaling, membrane trafficking, oxidative phosphorylation, and SNARE interactions in vesicular transport pathways (Fig. 1A-D). Based on the GSEA analysis, we hypothesized that P4H-TM is involved in the regulation of active vesicular transport via calcium signaling in the brain. QRT-PCR analyses showed upregulation of $\mathrm{P} 4 \mathrm{H}-\mathrm{TM}$ mRNA expression over time in mouse cortical tissue from embryonic day (E) 15 to one month of age (Fig. 1E). We chose to study the role of $\mathrm{P} 4 \mathrm{H}$-TM further in primary astrocyte cultures established from postnatal day $(\mathrm{P}) 1$ to $\mathrm{P} 2$ cortexes. Expression of $\mathrm{P} 4 \mathrm{H}-\mathrm{TM}$ mRNA in these cells was verified by qRT-PCR (Fig. 1E), confirming their suitability for functional studies of $\mathrm{P} 4 \mathrm{H}$ TM.

As the microarray data indicated alterations in the expression of genes involved in calcium signaling in the P $4 \mathrm{~h}-\mathrm{tm}^{-1-}$ mouse cortex relative to WT (Fig. 1A), including several $\mathrm{Ca}^{2+}$ transporting ATPases, we next analyzed 

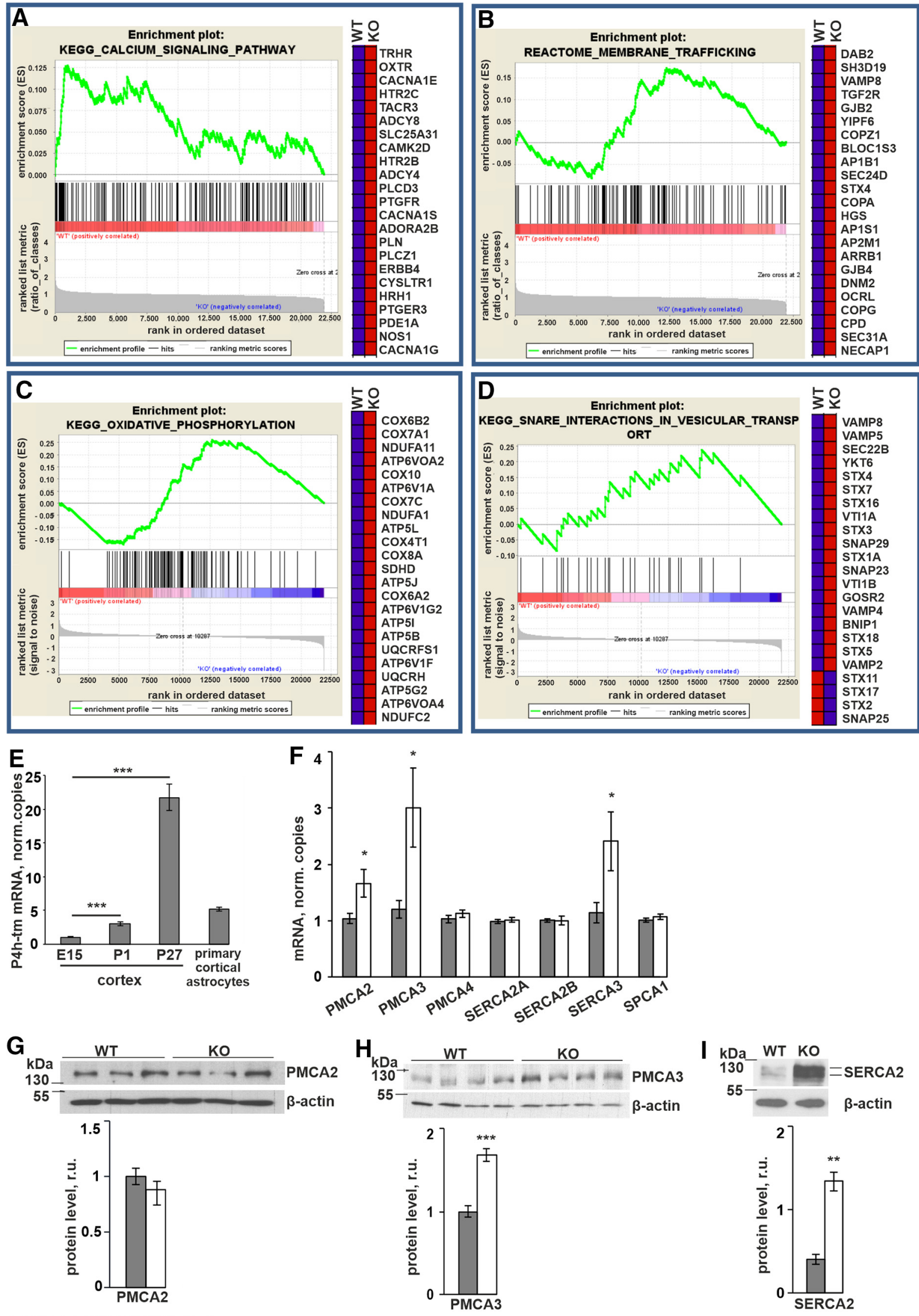

$\square$ WT $\square$ P4H-TM KO in E - I 
continued

Figure 1. Microarray data suggest that $\mathrm{P} 4 \mathrm{H}-\mathrm{TM}$ regulates calcium signaling. $\boldsymbol{A}-\boldsymbol{D}$, Male $\mathrm{P} 4 \mathrm{H}-\mathrm{TM}$ KO mice and their WT littermates were killed at the age of 2.5 months, and cortexes were collected for microarray analysis. Gene expression was compared between WT and KO and significantly enriched datasets were selected according to GSEA with default settings, i.e., $p<0.05$. Red color represents upregulated and blue color downregulated genes. Four individual mice were used per genotype in the experiment. Enrichment scores with a ranked list metrics (left) and heat map of 23 leading edge genes (right) are shown for the following biological pathways: $(\boldsymbol{A})$ GSEA for calcium signaling pathway, $(\boldsymbol{B})$ membrane trafficking, $(\boldsymbol{C})$ oxidative phosphorylation, and $(\boldsymbol{D})$ SNARE interactions in vesicular transport. $\boldsymbol{E}$, WT mice were killed either for dissection of cortexes or for isolation of primary cortical astrocytes. Cortexes were isolated from E15, P1, and P27 mice, while primary astrocytes were isolated from P1 to P2 mice and cultured for $10 \mathrm{~d}$ for P4h-tm mRNA analysis by qRT-PCR; $n=4$ mice for tissue dissection per time point and $n=3$ individual cultures per genotype, 6 mice per genotype. $\boldsymbol{F}$, qRT-PCR analysis of mRNA expression of different calcium pumps in primary cortical astrocytes. Plasma membrane calcium ATPase 2 (PMCA2) and 3 (PMCA3) and ER calcium ATPase 3 (SERCA3) mRNAs were found to be upregulated in P4H-TM KO versus WT cells; $n=9-12$, 4 individual cultures per genotype with two to three technical replicates each, 12 mice per genotype. G-I, Western blot analysis of expression of PMCA2 (G), PMCA3 (H), and SERCA2 (I) proteins in P4HTM KO versus WT primary cortical astrocytes. Representative blots are shown (upper panels) and the intensity of bands is quantitated by densitometry (lower panels), $n=3-4$ individual cultures per genotype, $6-8$ mice per genotype. $\beta$-Actin represents a loading control in $\boldsymbol{G}, \boldsymbol{I}$, while in $\boldsymbol{H}$, it represents a control of equal protein amount in the samples, because the high amount of protein needed for PMCA3 detection resulted in overloading of $\beta$-actin, and it therefore could not be analyzed from the same gel. Data information: data $(E-I)$ are presented as mean \pm SEM; ${ }^{*} p<0.05,{ }^{* *} p<0.01,{ }^{* *} p<0.001$ (Student's $t$ test). r.u., relative unit.

the expression of various $\mathrm{Ca}^{2+}$ ATPases in the cultured astrocytes by qRT-PCR. The results showed mRNA upregulation of the plasma membrane $\mathrm{Ca}^{2+}$ ATPases PMCA2 and PMCA3 and the sarcoplasmic/ER $\mathrm{Ca}^{2+}$ ATPase SERCA3 isoform in P4h-tm ${ }^{-1-}$ astrocytes (Fig. 1F). No difference in the expression of SPCA1 or PMCA4, SERCA2A or SERCA2B mRNA was observed between the genotypes (Fig. 1F). At protein level, upregulation of PMCA3, but not PMCA2, was confirmed by Western blotting in $P 4 \mathrm{~h}_{-\mathrm{tm}^{-1-}}$ cells relative to WT (Fig. 1G,H). We analyzed expression of SERCA by antibodies against SERCA2 and SERCA3 and detected upregulation of SERCA2 protein in P4h-tm ${ }^{-/-}$cells relative to control despite no changes in the mRNA level between the genotypes (Fig. $1 F, I)$. Variable and nonreproducible results depending on the antibody source were obtained for SERCA3 expression and thus conclusions of SERCA3 protein expression level could not be made.

\section{Receptor-mediated and store-operated calcium entry (SOCE) and the ER calcium content is affected in P4h- tm $^{-\prime-}$ astrocytes}

We next studied the effect of $\mathrm{P} 4 \mathrm{H}-\mathrm{TM}$ on calcium signaling by monitoring the changes in intracellular free calcium concentration $\left(\left[\mathrm{Ca}^{2+}\right]_{\mathrm{i}}\right)$ in WT and $\mathrm{P} 4 \mathrm{~h}-\mathrm{tm}^{-1-}$ astrocytes loaded with the calcium indicator Fluo-4. The increase in $\left[\mathrm{Ca}^{2+}\right]_{i}$ can be evoked in astrocytes via two different mechanisms: receptor-operated calcium entry (ROCE) and SOCE (Berridge et al., 2000; Clapham, 2007; Rivera et al., 2016; Papanikolaou et al., 2017). To investigate the possibility that $\mathrm{P} 4 \mathrm{H}-\mathrm{TM}$ affects ROCE, we stimulated the cells with ATP (King et al., 1996; Fischer et al., 2009; Fig. 2A). The ATP-evoked calcium response was substantially attenuated in the $P 4 h-\mathrm{tm}^{-/-}$cells relative to WT (Fig. 2B). The difference in the response was abolished by addition of 2-APB, an inhibitor of ROCE (Bootman et al., 2002; Fig. 2B). Treatment of the cells with TG, a potent SERCA inhibitor that depletes intracellular calcium stores and evokes substantial SOCE in astrocytes (Calloway et al., 2010), showed a significantly higher response in the $P 4 h-\mathrm{tm}^{-1-}$ astrocytes (Fig. 2B), suggesting increased SOCE in $P 4 h-\mathrm{tm}^{-1-}$ astrocytes relative to WT.

To determine whether the observed effects were a specific outcome of the $\mathrm{KO}$ of $\mathrm{P} 4 \mathrm{H}-\mathrm{TM}$ or whether the other $\mathrm{HIF}$ regulating $\mathrm{P} 4 \mathrm{Hs}$ contribute to it, we next studied calcium entry in astrocytes isolated from Hif-p $4 h-1^{-1-}$, Hif$p 4 h-3^{-1-}$, and Hif-p $4 h-2$ hypomorph mice. No differences were detected in the ATP-induced calcium response in these mutant astrocytes in comparison to WT (Fig. 2C-E), suggesting that the effect of $\mathrm{P} 4 \mathrm{H}-\mathrm{TM}$ on ROCE is unique among the HIF regulating $\mathrm{P} 4 \mathrm{Hs}$. However, SOCE was affected in Hif-p4h-2 hypomorph astrocytes, but not in Hif-p $4 h-1^{-1-}$ or Hif-p $4 h-3^{-1-}$ astrocytes (Fig. $2 C-E$ ), HIF$\mathrm{P} 4 \mathrm{H} 2$ hypomorph cells having a significantly higher response to TG (Fig. 2D). The HIF-P4H-2 mRNA expression level in the primary Hif-p4h-2 hypomorph astrocytes was $\sim 20 \%$ of that in WT astrocytes $(0.21 \pm 0.02$ r.u. in HIF$\mathrm{P} 4 \mathrm{H}-2$ hypomorph cells vs $1.00 \pm 0.08$ r.u. in WT cells, $n=3$ individual cultures isolated from six mice per genotype, cells from two mice pooled per culture, $p<0.001$ by Student's $t$ test, qRT-PCR data). P4H-TM and HIF-P4H2 thus apparently share some overlapping molecular mechanisms to regulate SOCE and the role of HIF-P4H-2 in the regulation of calcium signaling should be a topic for further investigation.

To dissect further the effect of P4H-TM KO on SOCE, we monitored calcium influx in Fluo-4-loaded cells after depleting ER calcium stores with TG in EGTA-containing buffer followed by superfusion with calcium-containing buffer (Berridge et al., 2000; Papanikolaou et al., 2017). Under these experimental conditions, virtually all extracellular calcium is chelated, and the TG-evoked increase in $\left[\mathrm{Ca}^{2+}\right]_{\mathrm{i}}$ is generated by depletion of intracellular stores only and is thus proportional to the ER calcium content. A subsequent readdition of calcium induces an increase in $\left[\mathrm{Ca}^{2+}\right]_{i}$ exclusively by massive influx through the SOCE channels. The $\mathrm{P} 4 \mathrm{~h}-\mathrm{tm}^{-1-}$ astrocytes had a significantly higher TG-evoked rise in $\left[\mathrm{Ca}^{2+}\right]_{\mathrm{i}}$ relative to WT (Fig. $2 F, G)$. This suggested that the calcium content within the $\mathrm{ER}$ is higher in $\mathrm{P} 4 \mathrm{~h}-\mathrm{tm}^{-1-}$ cells. The signal from readdition 


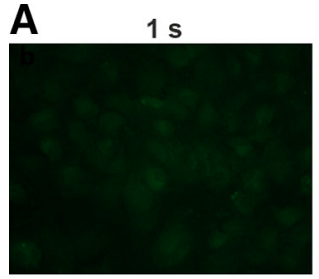

before ATP
$21 \mathrm{~s}$

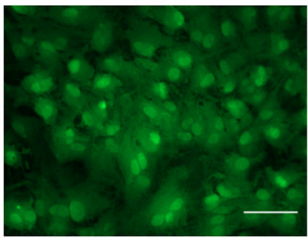

$120 s$

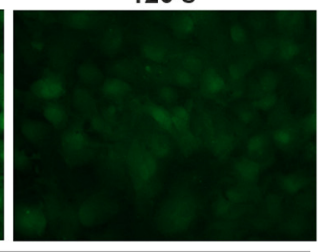

after ATP
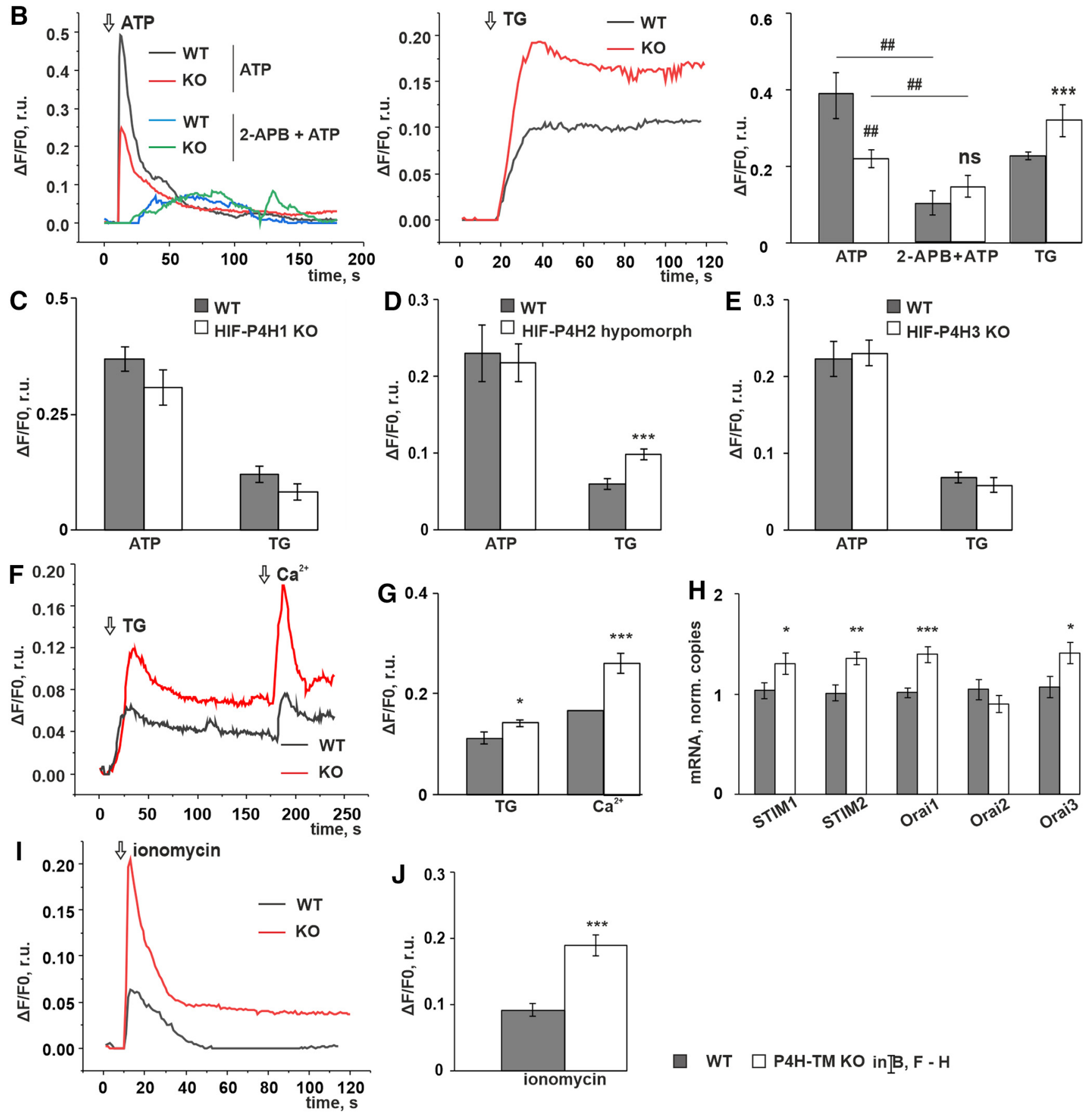

Figure 2. $\mathrm{P} 4 \mathrm{H}-\mathrm{TM}$ inactivation affects agonist-evoked changes in cytosolic calcium concentrations. $\boldsymbol{A}-\boldsymbol{F}, \boldsymbol{H}$, Primary cortical astrocytes were isolated from P4H-TM KO and WT mice and loaded with Fluo-4. Representative traces of P4H-TM KO and WT astrocytes are shown on the graphs. Changes in cytosolic calcium $\left[\mathrm{Ca}^{2+}\right]$ i peak or plateau amplitudes are shown in the diagrams. $\boldsymbol{A}-\boldsymbol{E}$, 
continued

The increase in $\left[\mathrm{Ca}^{2+}\right] \mathrm{i}$ was evoked by either ATP $(100 \mu \mathrm{m})$ or TG $(10 \mu \mathrm{m})$ in a calcium-containing buffer. $\boldsymbol{A}$, Fluorescence of the Fluo-4 calcium indicator captured by a spinning disk confocal microscope. Panels show a time point before the treatment and two time points after stimulation with ATP and illustrate a massive increase in the signal a few seconds after addition of ATP, followed by a subsequent decay. Scale bar: $60 \mu \mathrm{m}$. B, Changes in $\left[\mathrm{Ca}^{2+}\right] \mathrm{i}$ in $\mathrm{P} 4 \mathrm{H}-\mathrm{TM}$ KO versus WT astrocytes on treatment with ATP, 2APB + ATP, and TG. In 2-APB + ATP the cells were preincubated with 2-APB (25 $\mu \mathrm{m}$; inhibitor of IP3R) 2 min before ATP addition; $n=46$ cells per genotype in ATP, $n=14$ cells per genotype in 2-APB-2 + ATP and $n=46-61$ cells per genotype in TG, 4 mice per genotype. $\boldsymbol{C}-\boldsymbol{E}$, Changes in $\left[\mathrm{Ca}^{2+}\right] \mathrm{i}$ in HIF-P4H1 KO $(\boldsymbol{C}, n=20$ cells in ATP and $n=13-18$ cells in TG per genotype, 3 mice per genotype), HIF-P4H2 hypomorph ( $\boldsymbol{D}, n=15-19$ cells per genotype, 3 mice per genotype), and HIF-P4H3 KO (E, $n=18-25$ cells per genotype, 3 mice per genotype) versus corresponding WT after stimulation with either ATP or TG. $\boldsymbol{F}$, G, TG-evoked changes in $\left[\mathrm{Ca}^{2+}\right] \mathrm{i}$ in P4H-TM KO and WT astrocytes in EGTA (2 mM)-containing buffer and the effect of readdition of $20 \mathrm{~mm}$ calcium, $n=31-35$ cells per genotype, 4 mice per genotype. $\boldsymbol{H}$, qRT-PCR analysis of Stim and Orai isoform mRNA levels in P4H-TM KO and WT astrocytes, $n=7-11,3-4$ individual cultures per genotype with one to three technical replicates each, 9-12 mice per genotype. I,J, Changes in $\left[\mathrm{Ca}^{2+}\right] \mathrm{i}$ in P4H-TM KO and WT astrocytes evoked by ionomycin (1 $\left.\mu \mathrm{M}\right)$ in the presence of EGTA (2 mM) in the buffer, $n=23-31$ cells per genotype, 3 mice per genotype. Data information: data are presented as mean \pm SEM in $\boldsymbol{B}-\boldsymbol{J}$; \#\#p $<0.01$ by Tukey's HSD test after one-way ANOVA method for multiple comparisons; ${ }^{*} p<0.05,{ }^{* *} p<0.01$, ${ }^{* * *} p<0.001$ by Student's $t$ test. r. u., relative unit. ns, not significant.

of calcium was higher in the P4h-tm ${ }^{-1-}$ astrocytes (Fig. $2 F, G)$, confirming enhanced SOCE in $\mathrm{P} 4 \mathrm{H}-\mathrm{TM} \mathrm{KO}$ relative to WT cells. qRT-PCR analysis of the mRNA expression of the main proteins involved in SOCE (Gao et al., 2016; Kwon et al., 2017) showed that mRNA levels for STIM1, STIM2, ORAI1 and ORAI3 were upregulated in the P4h$\mathrm{tm}^{-1-}$ astrocytes relative to WT (Fig. $2 \mathrm{H}$ ), being in line with the live-cell calcium imaging data.

To further investigate the possibility that $\mathrm{P} 4 \mathrm{H}-\mathrm{TM}$ deficiency affects the calcium content of the ER, we stimulated the cells in the presence of EGTA with ionomycin, a potent, highly selective calcium ionophore, that induces an increase in $\left[\mathrm{Ca}^{2+}\right]_{i}$ primarily by physicochemical translocation of calcium through the lipid bilayer of intracellular stores with only minor contribution of the ROCE pathway (McCollum et al., 2004; Müller et al., 2013). Since the translocation occurs according to the calcium gradient, the peak of the response to ionomycin is proportional to the ER calcium content. The response to ionomycin was significantly higher in the $P 4 h_{-1 m^{-1}}$ astrocytes relative to WT (Fig. 2l, J). Taken together, our results show that the ER calcium content is higher in $\mathrm{P} 4 \mathrm{~h}-\mathrm{tm}^{-1-}$ astrocytes, and thus cannot explain the observed lower ROCE (Fig. $2 B$ ) in the $P 4 h-\mathrm{tm}^{-1-}$ astrocytes relative to WT, which therefore must result from some other mechanism.

\section{Re-uptake of calcium by mitochondria on ATP treatment is significantly higher in P4H-TM KO astrocytes}

The reduced ATP-evoked ROCE in P4h-tm ${ }^{-1-}$ astrocytes relative to WT is intriguing, as based on the higher ER calcium content in the P4h-tm ${ }^{-1-}$ astrocytes when compared with WT, an opposite effect could be expected. Nevertheless, the $\left[\mathrm{Ca}^{2+}\right]_{i}$ response on ROCE is a net result of calcium entry from the extracellular milieu, and both the release of calcium from intracellular stores and uptake of calcium by other organelles, such as mitochondria, acting as calcium sinks (Filadi et al., 2017). Therefore, we next studied mitochondrial calcium uptake in $P 4 h-\mathrm{tm}^{-1-}$ astrocytes by analyzing simultaneously calcium release from the ER and calcium accumulation within mitochondria using genetically-encoded calcium indicators (GECls) entrapped in ER and mitochondria, respectively (Suzuki et al., 2014,
2016). Astrocytes were co-transfected with ER-targeted red fluorescent R-CEPIA1er and mitochondria-targeted green-fluorescent G-CEPIA2mt, followed by live-cell imaging on ATP stimulation at $24 \mathrm{~h}$ posttransfection. Changes in red and green fluorescent signal proportional to changes in free calcium concentration inside ER and mitochondria, $\left[\mathrm{Ca}^{2+}\right]_{\mathrm{er}}$ and $\left[\mathrm{Ca}^{2+}\right]_{\mathrm{m}}$, respectively, were calculated, and an ATP-induced decrease in $\left[\mathrm{Ca}^{2+}\right]_{\mathrm{er}}$ accompanied with an increase in $\left[\mathrm{Ca}^{2+}\right]_{\mathrm{m}}$ was observed (Fig. $3 A$ ). The maximum amplitude of the ER response was significantly higher in $P 4 \mathrm{~h}_{-\mathrm{tm}^{-1}}$ astrocytes than in WT (Fig. $\left.3 A, B\right)$. Since $\left[\mathrm{Ca}^{2}\right.$ $\left.{ }^{+}\right]_{\mathrm{er}}$ at the resting state was used as a normalization value, this result is in accordance with the higher calcium content inside the ER in P4h-tm ${ }^{-1-}$ cells. As is evident from the fluorescent plot, the kinetics of calcium release from the ER was faster in $\mathrm{P} 4 \mathrm{H}-\mathrm{TM} \mathrm{KO}$ cells (Fig. $3 \mathrm{~A}$ ). The maximum amplitude of the mitochondria response in $\mathrm{P} 4 \mathrm{~h}-\mathrm{tm}^{-1-}$ astrocytes was likewise more profound than in the WT cells (Fig. $3 A, C)$, indicating higher mitochondrial uptake of calcium in the mutant cells. Furthermore, the time to reach a maximum response was significantly longer in the mutant cells in comparison to WT cells (Fig. 3D). Interestingly, both the ER and mitochondria responses to addition of ATP started significantly faster in $\mathrm{P} 4 \mathrm{~h}$ - $\mathrm{tm}^{-1-}$ astrocytes in comparison to WT cells (Fig. 3E, 1.43 and $1.61 \mathrm{~s}$ faster, respectively). The higher mRNA levels for mitochondrial calcium uniporter (MCU), mitochondrial calcium uptake 1 (MICU1), and MCU regulator 1 (MCUR1; Fig. 3F), i.e., the proteins regulating mitochondrial calcium uptake (Perocchi et al., 2010; Filadi et al., 2017), could suggest higher protein expression, and in part explain the higher uptake of calcium in P4h-tm ${ }^{-1-}$ astrocytes.

Taken together, $\mathrm{P} 4 \mathrm{H}-\mathrm{TM} \mathrm{KO}$ mitochondria have a higher ATP-induced calcium uptake capacity than the WT cells. Therefore, it is likely that the higher mitochondrial uptake overrides the higher release of calcium from the $\mathrm{ER}$, the net effect being a decrease in the ATP-evoked changes in $\left[\mathrm{Ca}^{2+}\right]_{\mathrm{i}}$ in the mutant cells relative to WT cells.

\section{Expression of calcium leak channels is increased in P4H-TM KO astrocytes}

In the resting state, the calcium content of the ER reflects a balance between active uptake by SERCA and 


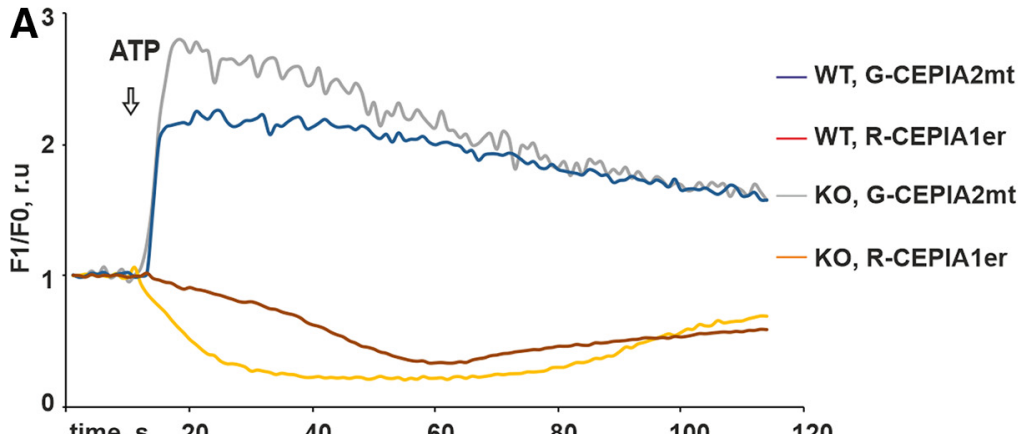

B
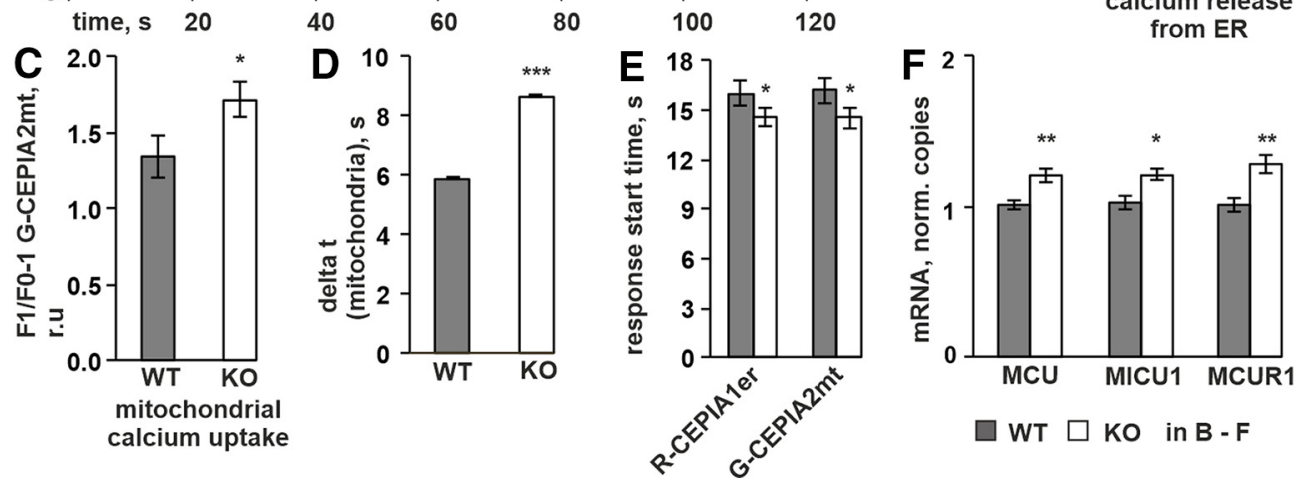

Figure 3. $\mathrm{P} 4 \mathrm{H}-\mathrm{TM} \mathrm{KO}$ affects mitochondrial and ER calcium dynamics in response to ATP. A-E, P4H-TM KO and WT primary cortical astrocytes were co-transfected with G-CEPIA2mt (to measure mitochondrial calcium concentration) and R-CEPIA1er (to measure changes in ER calcium concentration), and fluorescence intensity was recorded during time-lapse imaging in a calciumcontaining buffer. The astrocytes were stimulated with $100 \mu \mathrm{M}$ ATP. Analysis of time-lapse images was done on $n=26$ cells per genotype, 6 mice per genotype. A, Representative traces of the ATP-induced changes in ER and mitochondrial calcium concentrations. Time course of F1/F0 ER calcium signal indicates red fluorescence decrease on ATP treatment proportional to decrease of free calcium amount inside the ER. Time course of F1/F0 mitochondrial calcium signal indicates sudden increase in green fluorescence on ATP treatment proportional to rapid accumulation of calcium inside mitochondria. In the majority of cells, decrease in ER calcium signal preceded increase in mitochondria calcium signal. $\boldsymbol{B}-\boldsymbol{D}$, Amplitudes of ER and mitochondria calcium response to ATP were defined as maximum change in F1/F0 (fluorescence intensity after ATP application normalized by the resting value) within a 2-min time window after ATP application. $\boldsymbol{B}$, The ATP-evoked release of ER calcium was higher in P4H-TM KO astrocytes. $\boldsymbol{C}$, The ATP-evoked increase in mitochondrial calcium was higher in P4H-TM KO astrocytes. $\boldsymbol{D}$, Time necessary for mitochondria to reach the maximum amplitude of calcium response starting from the resting level. $\boldsymbol{E}$, Time point when the red fluorescence (ER signal) starts to decrease and the green fluorescence (mitochondrial signal) starts to increase on ATP treatment. The data indicate that $\mathrm{P} 4 \mathrm{H}-\mathrm{TM} \mathrm{KO}$ astrocytes overall react faster to ATP stimulation than WT astrocytes. $\boldsymbol{F}$, qRT-PCR analysis of mRNA levels for the mitochondrial uniporter channel complex components MCU, MICU1, and MCUR1 in P4H-TM KO and WT astrocytes, $n=8-12,3-4$ individual cultures per genotype with two to three technical replicates each, 9-12 mice per genotype. Data information: data are presented as mean \pm SEM in $\boldsymbol{B}-\boldsymbol{F} ;{ }^{*} p<0.05,{ }^{* *} p<0.01,{ }^{* *} p<0.001$ by Student's $t$ test. r.u., relative unit.

passive efflux through leak channels such as translocon during protein translation and inositol trisphosphate receptor (IP3R) in its unstimulated stage in astrocytes (Szlufcik et al., 2006; Lang et al., 2017). We next analyzed calcium leakage by inhibiting SERCA pumps with TG simultaneously with pharmacological inhibition of the leak channels. Our data show that pretreatment with anisomycin, an inhibitor of translation that makes the translocon calcium-impermeable, significantly reduced the TG-induced calcium signal in both P4H-TM KO and WT astrocytes, but the difference between the genotypes remained (Fig. 4A). Since anisomycin was added $10 \mathrm{~min}$ before TG, the pretreatment time is too short for marked changes in protein levels because of inhibition of translation (Aakalu et al., 2001; Claydon and Beynon, 2012), thus the effect can be attributed at least mostly to the inhibition of calcium permeability of the translocon. On the other hand, treatment with 2-APB in a concentration which was efficient to block the response to ATP (Fig. 2B) and did not induce a calcium response by itself, was insufficient to block the TG-induced calcium signal (Fig. 4A). This suggests that the translocon complex acts as a main leak channel in cortical astrocytes. We next analyzed the effect of puromycin, an inhibitor of translation that blocks the translocon in a calcium permeable way and evokes luminal calcium leakage exclusively through translocon (Van Coppenolle et al., 2004). A higher puromycin-induced calcium leakage was observed in P4h-tm ${ }^{-1-}$ cells relative to WT in EGTA-containing buffer (Fig. 4B), indicating higher leakage through translocon. This finding was supported by increased mRNA expression levels for the translocon components SEC61A, SEC61B, and SEC61G (Fig. 4C), which was also manifested as a higher protein expression level in the case of SEC61G (Fig. 4D,E) in $P 4 h-\mathrm{tm}^{-/-}$cells relative to WT.

TG-induced translocon-associated calcium loss is also known to contribute to ER stress response modulation and the resulting Erk-elf $2 \alpha$ overactivation has been shown to be associated in astrocytes with a distinct 

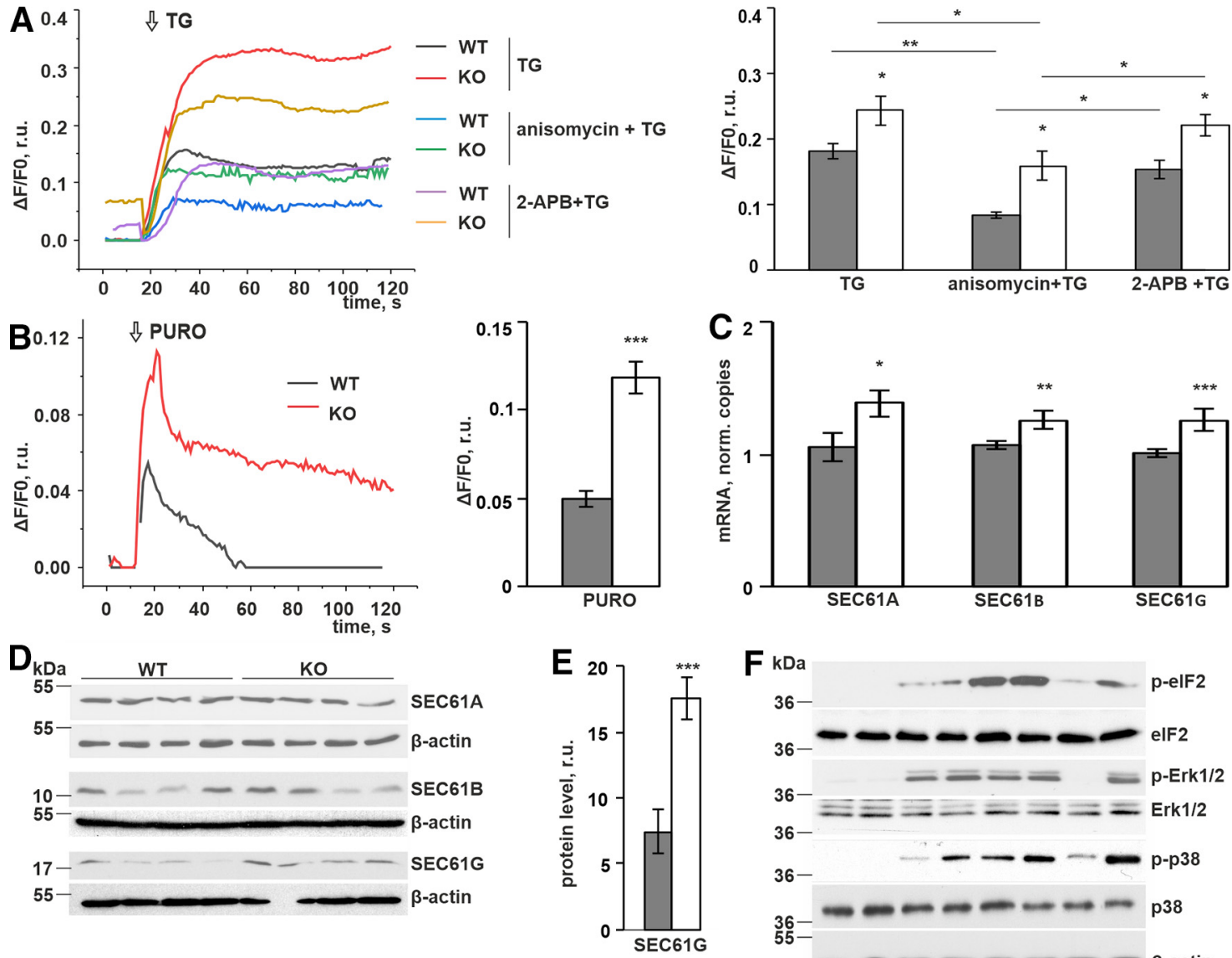

$\square W T \quad \square K O$ in A, B, C, E
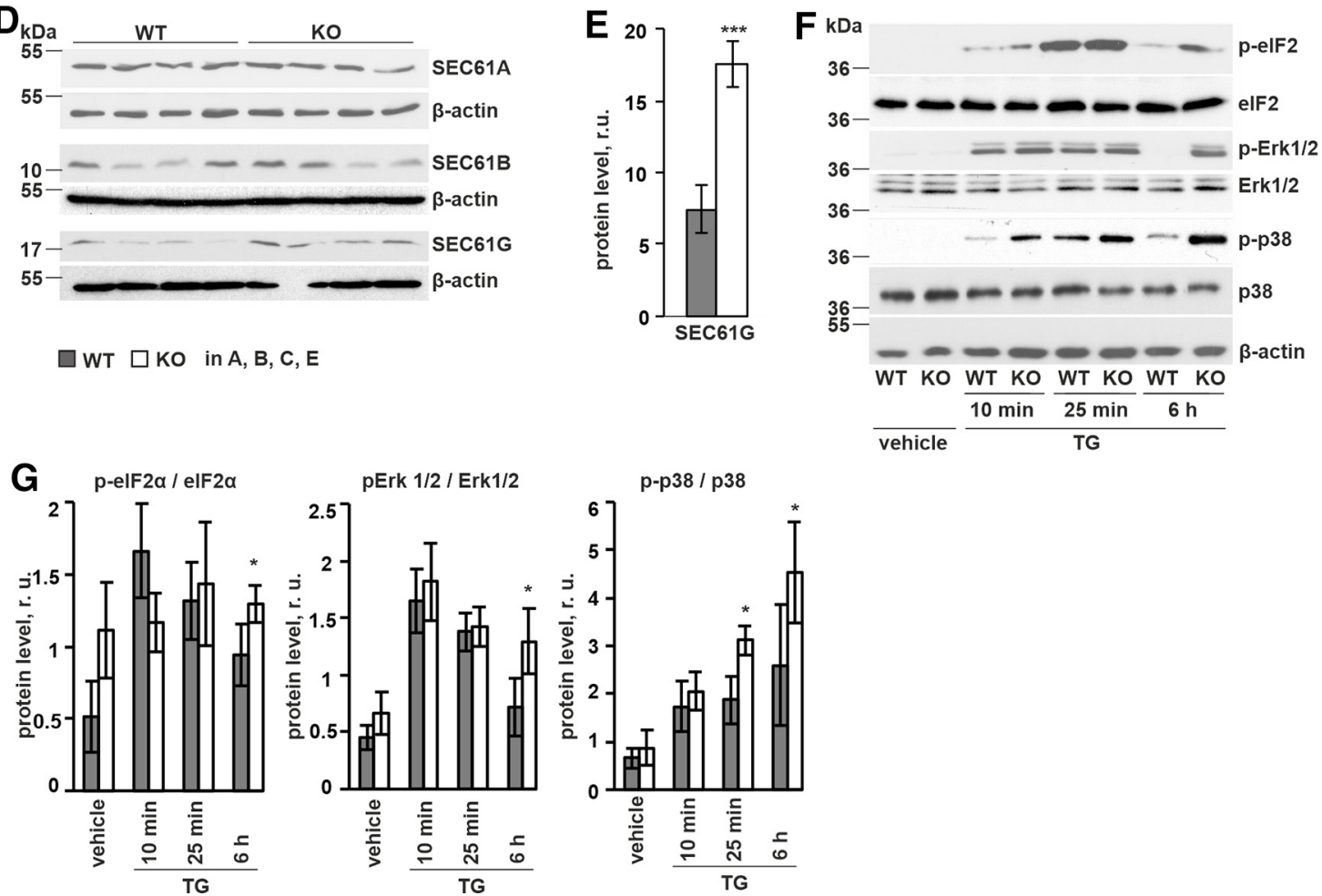

Figure 4. $\mathrm{P} 4 \mathrm{H}-\mathrm{TM} \mathrm{KO}$ affects passive calcium leak through translocon complex and IP3R. $\boldsymbol{A}, \boldsymbol{B}, \mathrm{P} 4 \mathrm{H}-\mathrm{TM}$ KO and WT primary cortical astrocytes were loaded with Fluo-4, and live cell calcium imaging was performed in the presence of the indicated pharmacological inhibitors. Representative traces of P4H-TM KO and WT astrocytes are shown on the graphs. Changes in cytosolic calcium $\left[\mathrm{Ca}^{2+}\right] \mathrm{i}$ peak or plateau amplitudes are shown in the diagrams. $\boldsymbol{A}$, The increase in $\left[\mathrm{Ca}^{2+}\right] \mathrm{i}$ evoked by stimulating the cells with TG (10 $\mu \mathrm{M})$ was attenuated by the translocon inhibitor anisomycin $(200 \mu \mathrm{M}, 10 \mathrm{~min}$ before TG), but not by the IP3R inhibitor $2-\mathrm{APB}(25 \mu \mathrm{M}$, 2 min before TG), $n=22-38$ cells per genotype, 5 mice per genotype per condition. Imaging was performed in a calcium-containing buffer. $\boldsymbol{B}$, Application of an inhibitor of translation (puromycin, PURO, $200 \mu \mathrm{M}$ ) induced a higher increase in $\left[\mathrm{Ca}^{2+}\right] \mathrm{i}$ in $\mathrm{P} 4 \mathrm{H}-\mathrm{TM} \mathrm{KO}$ astrocytes versus WT in EGTA-containing buffer, $n=16$ cells per genotype, 3 mice per genotype. $\boldsymbol{C}$, qRT-PCR analysis of mRNA expression levels for the translocon complex subunits SEC61 A, B, and G in P4H-TM KO and WT astrocytes, $n=7-12,3-4$ individual cultures per genotype with one to three technical replicates each, 9-12 mice per genotype. $\boldsymbol{D}, \boldsymbol{E}$, Western blot analysis of expression of translocon subunits SEC61 A, B, and G, in P4H-TM KO and WT astrocytes. Representative Western blots (D) and their quantification, $n=4$ individual cultures per genotype, 4 mice per genotype $(\boldsymbol{E})$ are shown. $\beta$-Actin represents a loading control. $\boldsymbol{F}$, $\boldsymbol{G}$, Western blot analysis of phosphorylation of elF2a and Erk1/2 and p38 kinases in P4H-TM KO and WT astrocytes after treatment with $10 \mu \mathrm{M}$ TG for the indicated time points. Representative Western blots $(\boldsymbol{F})$ of the phospho and total forms are shown. $\beta$-Actin is shown to confirm equal protein amount in the samples. Western blot quantification, $n=3-4$ individual cultures per genotype, 3-4 
continued

mice per genotype $(\boldsymbol{E})$ are shown. Data information: data are presented as mean \pm SEM in $\boldsymbol{A}-\boldsymbol{C}, \boldsymbol{E}$. In $\boldsymbol{A}:{ }^{*} p<0.05,{ }^{* *} p<0.01$ by Holm test after one-way ANOVA for multiple comparisons. In $\boldsymbol{B}, \boldsymbol{C}, \boldsymbol{E}, \mathbf{G}$ : ${ }^{\star} p<0.05,{ }^{\star \star} p<0.01$, ${ }^{\star \star \star} p<0.001$ by Student's $t$ test. r.u., relative unit.

pathogenic reactivity state and decreased secretome (Kamiya et al., 2011; Johnson et al., 2014; Martin-Jiménez et al., 2017; Smith et al., 2020). Therefore, we next analyzed the effect of $\mathrm{P} 4 \mathrm{H}-\mathrm{TM}$ loss on the induction and persistence of Erk and elF2 $\alpha$ phosphorylation under TG treatment. The TG-induced phosphorylation of Erk and elF2 $\alpha$ has a temporal pattern, the initial increase in phosphorylation plateauing typically at around $2 \mathrm{~h}$ followed by a progressive decrease (Smith et al., 2020). No significant difference between the genotypes was observed in the initial phase of the phosphorylation response in the presence of TG, but the phosphorylation of elF2 and Erk1/2 remained at a higher level in the $P 4 h-\mathrm{tm}^{-1-}$ cells at a later time point $(6 \mathrm{~h})$ when compared with WT (Fig. 4F,G). Furthermore, the p38 MAPK pathway is known to respond to various cellular and extracellular stress signals and is activated by TG treatment (Kim et al., 2010; Darling and Cook, 2014; Huang et al., 2014). Therefore, we also studied p38 kinase activation on TG treatment. Higher activation of p38 was evident in the P4h-tm ${ }^{-/-}$when compared with WT cells especially at later time points (Fig. 4F,G). In conclusion, the data show upregulated leak channel expression and higher passive calcium leakage from the ER to the cytosol as well as changes in temporal kinase phosphorylation patterns, which could indicate enhanced susceptibility to ER stress in $P 4 h-\mathrm{tm}^{-1-}$ astrocytes. Detailed analyses of the effects of $\mathrm{P} 4 \mathrm{H}-\mathrm{TM}$ inactivation on the induction of ER stress with various stress inducers, markers and outcomes should be addressed in future studies.

\section{Calcium-dependent vesicular exocytosis is decreased in P4H-TM KO astrocytes}

In response to stimulation with ATP, astrocytes release several chemical substances, termed gliotransmitters, which affect neuronal communication pathways (Parpura and Zorec, 2010; Zorec et al., 2012, 2016). Regulated, calcium-dependent release of gliotransmitters from astrocytes occurs via vesicular exocytosis and one of the integral membrane proteins of the astrocytic secretory vesicles is Syb2 (Zorec et al., 2016). We next studied whether calcium-dependent vesicular exocytosis is affected in $\mathrm{P} 4 \mathrm{~h}-\mathrm{tm}^{-1-}$ astrocytes by transfecting the cells with Syb2-pHluorin, a fusion protein consisting of a $\mathrm{pH}-$ sensitive GFP mutant fused to the luminal C-terminal end of Syb2 (Miesenböck et al., 1998). Because the lumen of the vesicles is acidic, the fluorescence of Syb2-pHluorin increases on exocytosis because of $\mathrm{pH}$ neutralization (Miesenböck et al., 1998). We used TIRF imaging to monitor and quantify the membrane-proximal appearance and disappearance of pHluorin-labeled fluorescent puncta as the indicator of vesicular exocytosis evoked by ATP stimulation on vesicle-cytoplasmic membrane fusion. We also detected some TIRF signal already at baseline before ATP stimulation, but the interpretation of disappearance of fluorescent puncta at baseline is more difficult since clearance of the reporter from the cell surface can occur both via exocytosis and endocytosis. Although treatment of the astrocytes with ATP to stimulate calcium-dependent exocytosis resulted in an overall increase in the pHluorin fluorescence signal, the number of vesicular fusion events was lower in $\mathrm{P} 4 \mathrm{~h}$ - $\mathrm{tm}^{-1-}$ cells both at baseline and after ATP stimulation (Fig. 5A-C). To make sure that the decreased TIRF signal is not because of differences in Syb2 expression levels we confirmed by Western blotting using anti-GFP and anti-Syb2 antibodies that protein levels of Syb2-pHluorin as well as endogenous Syb2 are equal between genotypes (Fig. 5D,E). Taking into account that a transient increase in cytosolic calcium levels is sufficient and necessary for the engagement of calcium-sensitive effector proteins of the secretory machinery (Kreft et al., 2004; Zorec et al., 2012), our observation of decreased ATP-evoked vesicular exocytosis in the $P 4 h-\mathrm{tm}^{-1-}$ cells relative to WT is well in line with the attenuated ATPevoked ROCE in these cells.

\section{Intracellular ATP content is decreased in P4H-TM KO astrocytes}

As reported above, expression of calcium sequestering ATPases (Fig. 1F-l) and mitochondrial uptake of calcium (Fig. $3 A, C)$ were increased in $P 4 h-\mathrm{tm}^{-1-}$ astrocytes. Taking into account the high relative contribution of cellular ATPases to total ATP consumption (Smith et al., 2013) and the importance of ER-mitochondria calcium shuttling for mitochondrial ATP synthesis (Mallilankaraman et al., 2012a,b), we next analyzed intracellular ATP levels and ATPase activity in the $P 4 h-\mathrm{tm}^{-1-}$ astrocytes. The ATP content was significantly decreased, while ATPase activity was increased in whole-cell lysates of $P 4 h-\mathrm{tm}^{-1-}$ astrocytes relative to WT (Fig. $6 A, B$ ). The data on increased ATPase activity are consistent with the upregulated expression of calcium sequestering ATPases in $\mathrm{P} 4 \mathrm{~h}-\mathrm{tm}^{-1-}$ astrocytes.

Previously, it was reported that the ATP synthesis rate in mitochondria correlates with the oxygen consumption rate (Salin et al., 2015), as well as with the mitochondrial membrane potential (Kadenbach et al., 2011). Nevertheless, despite the effect on ATP content, our data revealed no effect of $\mathrm{P} 4 \mathrm{H}-\mathrm{TM} \mathrm{KO}$ on the respiratory capacity of astrocytes, either under normoxic conditions or under OGD $\left(1 \% \mathrm{O}_{2}\right.$ and no glucose for 20 h; Fig. 6C). Interestingly, mitochondrial membrane hyperpolarization, which is known to be induced by OGD as an adaptive attempt of astrocytes to increase ATP production to overcome ischemic stress (lijima, 2006; Korenić et al., 2014), was impaired in P4h$\mathrm{tm}^{-1-}$ astrocytes when compared with WT (Fig. 6D). These data indicate that ATP production is likely to be impaired in mitochondria when $P 4 h-\mathrm{tm}^{-1-}$ cells are challenged with OGD. 

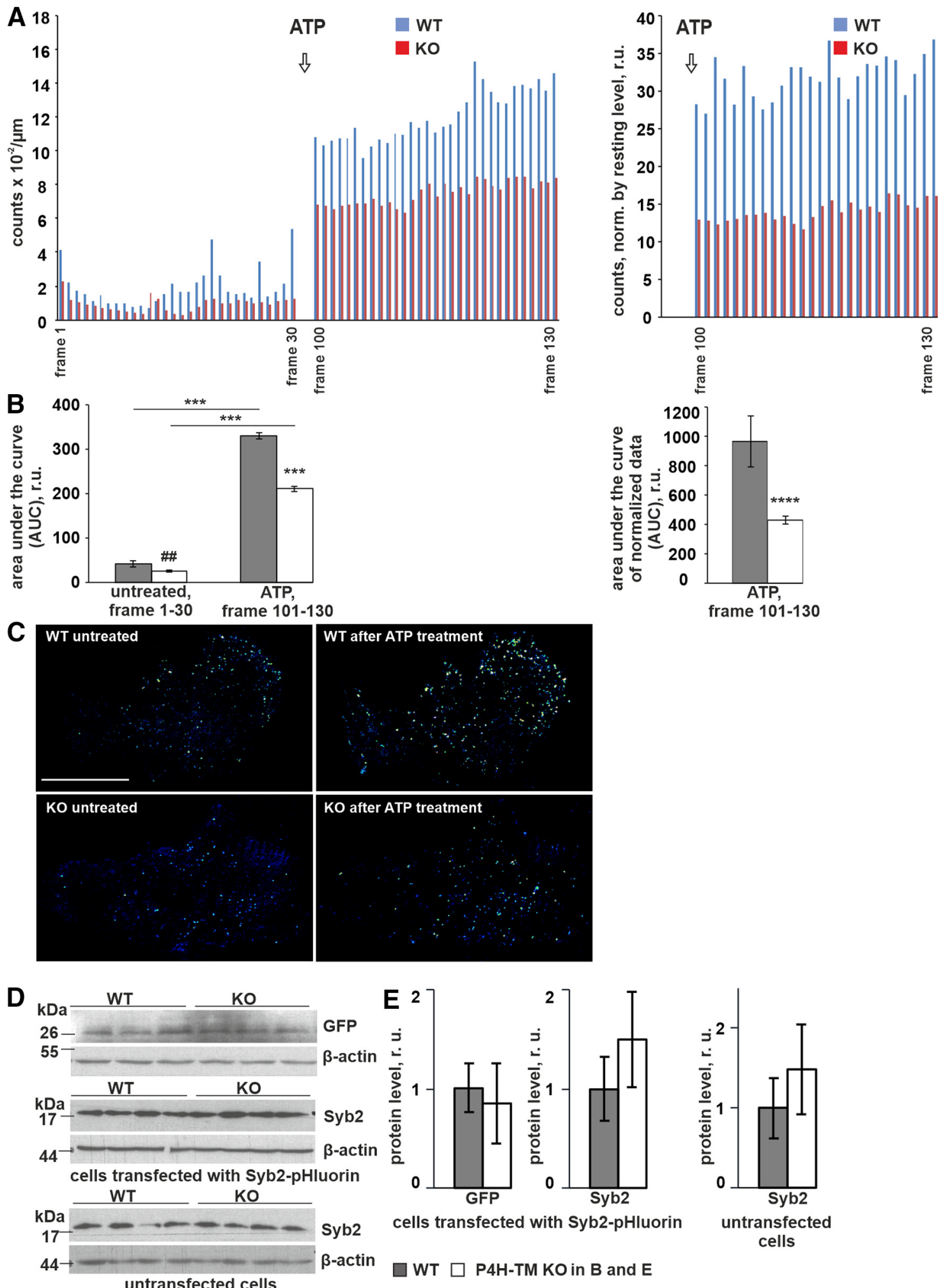

cells transfected with Syb2-pHluorin

untransfected cells

Figure 5. P4H-TM KO affects vesicular exocytosis induced by ATP. Primary cortical astrocytes were transiently transfected with Syb2-pHluorin to label small vesicles. To characterize the time course of vesicle release on the basal plasma membrane, time-lapse image series were generated by taking TIRF images every $1 \mathrm{~s}$ over $\sim 2 \mathrm{~min}$ (130 frames). Cells were treated with $100 \mu \mathrm{M}$ ATP to stimulate calcium-dependent exocytosis, and bright punctate that appeared and then disappeared in the evanescent field was classified as a fusion/release event. A, Analysis of TIRF images was done on 22-25 cells per genotype, 3 individual cultures per genotype, 6 mice per genotype. Number of fusion/release events, which is proportional to the exocytosis rate was quantified using ZEN and then ImageJ software. Each column indicates the average number of fusion/release events in each imaging frame. The number of 
continued

both spontaneous and ATP-induced fusion/release events (left panel) as well as the number of ATP-induced events normalized by spontaneous signal (right panel) was lower in P4H-TM KO astrocytes when compared with WT. Data are presented as mean. $\boldsymbol{B}$, Quantification of TIRF data displayed in panel $\boldsymbol{A}$. The area under the curve (AUC) was calculated using GraphPad Prism software from raw data (left panel) and from normalized data (right panel) from time 0 to $30 \mathrm{~s}$ (before ATP treatment, left panel) and from time 100 to $130 \mathrm{~s}$ (after ATP treatment, left and right panels) in P4H-TM KO and WT astrocytes, $n=22-25$ cells per genotype, 3 individual cultures per genotype, 6 mice per genotype. $\boldsymbol{C}$, Representative background subtracted ratio images of TIRF microscopy showing secretion of Syb2-pHluorin-positive vesicles on the basal plasma membrane. Panels show a time point before and after the ATP treatment and illustrate an overall lower exocytosis rate in P4H-TM KO astrocytes when compared with WT. Scale bar: $20 \mu \mathrm{m}$. $\boldsymbol{D}$, $\boldsymbol{E}$, Western blot analysis of GFP and Syb2 protein expression in untransfected cells and cells transfected with Syb2-pHluorin as indicated. Representative blots are shown $(\boldsymbol{D})$, and the intensity of bands is quantitated by densitometry $(\boldsymbol{E}), n=4$ individual cultures per genotype, 4 mice per genotype. $\beta$-Actin represents a loading control. Data information: data $(\boldsymbol{B})$ are presented as mean \pm SEM; $\# \# p<0.01$ and ${ }^{* \star \star \star} p<0.0001$ by Student's $t$ test; ${ }^{\star \star \star} p<0.001$ by Tukey's HSD test after one-way ANOVA method for multiple comparisons. Data $(\boldsymbol{E})$ are presented as mean \pm SEM, not significant by Student's $t$ test, r.u., relative unit.
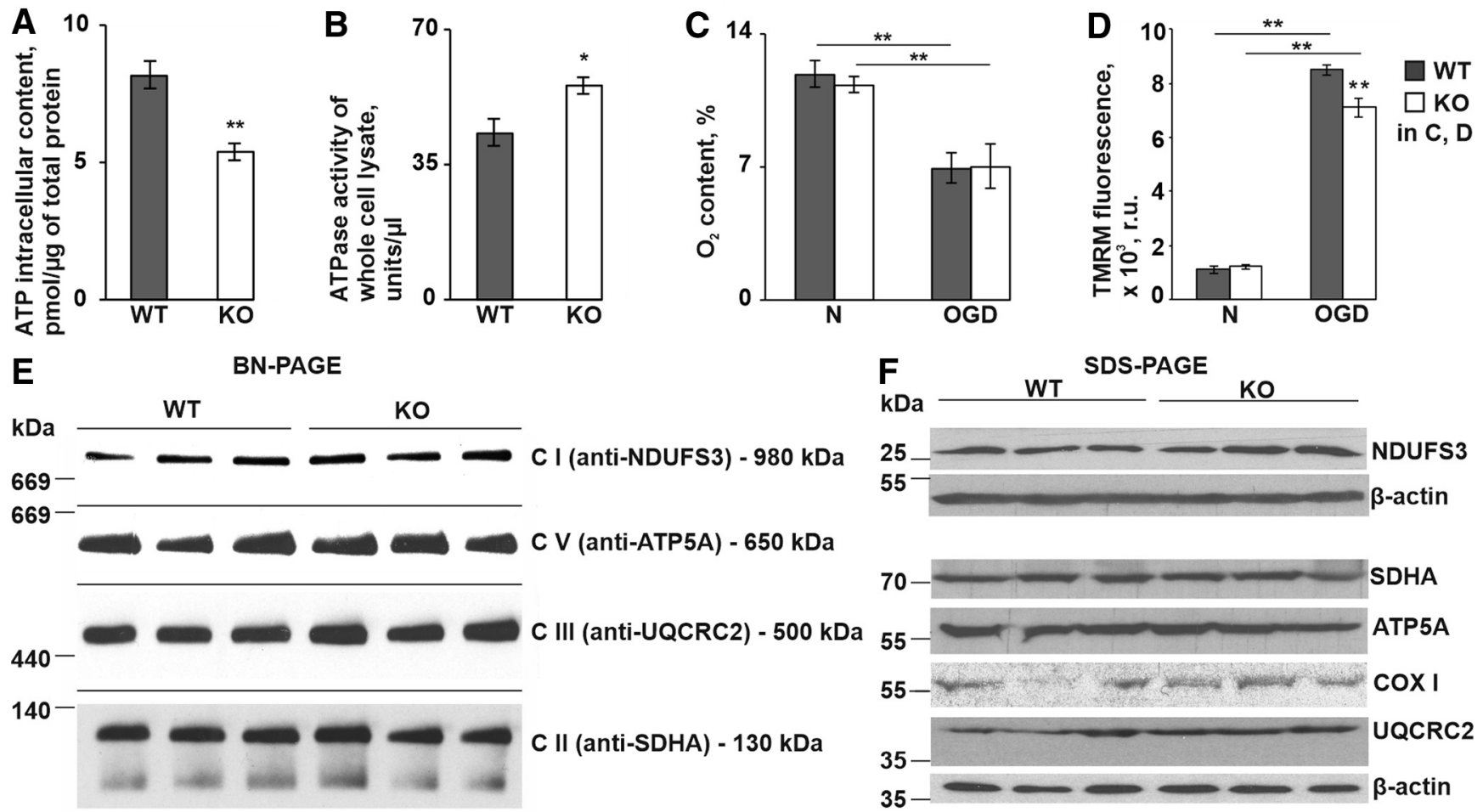

Figure 6. $\mathrm{P} 4 \mathrm{H}-\mathrm{TM} \mathrm{KO}$ affects intracellular ATP content, cellular ATPase activity and mitochondrial membrane potential, without an influence on the amount of mitochondrial respiratory complexes and $\mathrm{O}_{2}$ consumption. $\boldsymbol{A}-\boldsymbol{F}$, Experiments were carried on $\mathrm{P} 4 \mathrm{H}-\mathrm{TM} \mathrm{KO}$ and WT primary cortical astrocytes. $\boldsymbol{A}$, ATP content in whole-cell lysate, $n=5$ freshly prepared individual protein lysates per genotype, 5 mice per genotype. $\boldsymbol{B}$, Comparison of ATPase activity in whole-cell lysate, $n=9-10$ freshly prepared individual protein lysates, $4-5$ mice per genotype. $\boldsymbol{C}, \boldsymbol{D}$, Astrocytes were incubated in growth medium containing $1 \mathrm{~g} / \mathrm{l}$ glucose under normoxic conditions $(\mathrm{N})$ or in a medium containing no glucose under hypoxic $\left(1 \% \mathrm{O}_{2}\right)$ conditions $(\mathrm{OGD})$ for $20 \mathrm{~h}$. $\boldsymbol{C}$, Intracellular oxygen content within the astrocyte monolayer. Normoxic or hypoxic culture was conducted in the presence of the oxygen-sensitive probe MitoXpress-Intra $(10 \mu \mathrm{g} / \mathrm{ml})$. After $20 \mathrm{~h}$, time resolved fluorescence was measured on FLUOstar Omega microplate reader. Phosphorescent intensity of the probe was converted to $\mathrm{O}_{2}$ content using the plate reader software Mars; $n=4$ individual cultures per genotype, 4 mice per genotype per condition. $\boldsymbol{D}$. Analysis of mitochondrial membrane potential in living astrocytes. After $20 \mathrm{~h}$ of normoxia or OGD astrocytes were loaded with TMRM fluorescent dye (150 nM) for 5 min. Fluorescence was measured on FLUOstar Omega microplate reader. The signal reflects accumulation of TMRM in the mitochondrial membrane and is proportional to membrane potential; $n=4$ individual cultures per genotype, 4 mice per genotype per condition. $E$, BN-PAGE analysis of mitochondrial RC complexes in astrocytes. Mitochondrial protein complexes were separated on a $5 \%-15 \%$ BN-PAGE. Fully assembled Complexes I-V (Cl-CV) were assessed using antibodies against the Complex I 39-kDa subunit (NDUFS3), Complex II succinate dehydrogenase complex flavoprotein subunit A (SDHA), Complex III core protein 2 (UQCRC2), Complex IV cytochrome $c$ oxidase subunit I (COX I), and Complex V ATP synthase subunit $\alpha$ (ATP5A). The fully assembled Complex IV was under the detection limit. Representative blots of three individual cultures per genotype are shown. $\boldsymbol{F}$, SDS-PAGE and Western blot analysis of individual RC subunits in whole-cell protein lysates using the antibodies indicated in $\boldsymbol{E}$. $\beta$-Actin represents a loading control. Representative blots of three individual cultures per genotype are shown. Data information: data are presented as mean \pm SEM in $\boldsymbol{A}-\boldsymbol{D},{ }^{*} p<0.05,{ }^{* *} p<0.01$ by Student's $t$ test in $\boldsymbol{A}, \boldsymbol{B}$ and by Tukey's HSD test after oneway ANOVA method for multiple comparisons in $\boldsymbol{C}, \boldsymbol{D}$. r.u., relative unit. 
A significant depression of ATP synthesis is seen in isolated brain mitochondria after inhibition of the respiratory chain (RC) Complex I, III, or IV (Davey and Clark, 1996). We therefore next investigated the amount of $\mathrm{RC}$ complexes required for oxidative phosphorylation in $\mathrm{P} 4 \mathrm{~h}-\mathrm{tm}^{-/-}$cells. Fresh mitochondria were isolated from digitonin-treated astrocytes and the assembly of OXPHOS complexes was analyzed by BN-PAGE followed by Western blotting. No apparent differences in the amount of assembled Complexes I, II, III, and V were observed between the genotypes (Fig. 6E). Unfortunately, we were not able to detect the fully assembled Complex IV by BN-PAGE. However, immunoblotting of individual subunits from all the OXPHOS Complexes I-V, including COXI of Complex IV, indicated no difference between the amounts of protein in whole-cell lysates between the genotypes (Fig. $6 F$ ). Based on these data, it is unlikely that oxidative phosphorylation is affected in $\mathrm{P} 4 \mathrm{~h}-\mathrm{tm}^{-1-}$ cells at least under normoxic conditions and the observed increase in ATPase activity is a likely explanation for the decreased intracellular ATP level in P4h-tm ${ }^{-1-}$ astrocytes.

\section{Ultrastructural analysis of $\mathrm{P} 4 \mathrm{H}-\mathrm{TM} \mathrm{KO}$ astrocytes shows alterations in mitochondria and electron-lucent small vesicles}

As we observed differences in the vesicular exocytosis and ATP content in P4h-tm ${ }^{-1-}$ astrocytes, we next analyzed the number and morphology of mitochondria and vesicles by TEM (Fig. 7A). Our data revealed a decrease in the number of mitochondria per area (Fig. 7B) accompanied with enlargement of individual mitochondria (Fig. 7C) in $P 4 h-\mathrm{tm}^{-/-}$cells, with no effect on mitochondria length or degree of branching (Fig. $7 D, E$ ). The reduced number of mitochondria, but with increased size, is in accordance with the observed equal total OXPHOS subunit protein amount in both genotypes (Fig. 6F). In addition, immunostaining for Tom20 in the mitochondrial outer membrane showed that $P 4 \mathrm{~h}-\mathrm{tm}^{-1-}$ astrocytes were frequently essentially devoid of mitochondria in the distal cellular parts/ processes (Fig. $7 H, I)$, indicating changes in the distribution of mitochondria between the genotypes.

Analysis of electron-lucent small vesicular structures (SLMVs; Fig. 7A) showed that their number was significantly higher in P4h-tm ${ }^{-1-}$ astrocytes than in the WT (Fig. $7 F$ ), while no difference existed in the vesicle size between the genotypes (Fig. 7G). The majority of the vesicles was localized proximal to the plasma membrane and the average diameter was $\sim 74 \mathrm{~nm}^{2}$, which is in the size range $(30-100 \mathrm{~nm})$ reported for SLMVs (Vardjan and Zorec, 2015) that are known to contribute to the secretory vesicle population in astrocytes (Montana et al., 2006; Parpura and Zorec, 2010). The observed increased accumulation of SLMVs in the P4h-tm ${ }^{-1-}$ cells is likely to be a consequence of the less frequent exocytotic events (Fig. 5).

\section{HIF1 is involved in the P4H-TM-mediated regulation of calcium entry}

As P4H-TM has been previously shown to affect HIF1 signaling (Koivunen et al., 2007; Laitala et al., 2012;
Klotzsche-von Ameln et al., 2013; Leinonen et al., 2016) and as hypoxia is known to modulate calcium entry (Scott et al., 2015; Semenza and Prabhakar, 2015), we next analyzed the potential role of HIF1 and HIF2 in the P4H-TMmediated regulation of calcium entry. In line with previous observation of HIF1 $\alpha$ stabilization in $\mathrm{P} 4 \mathrm{~h}-\mathrm{tm}^{-/-}$cortical neurons (Leinonen et al., 2016), the amount of HIF1 $\alpha$ was higher also in the $\mathrm{P} 4 \mathrm{~h}$ - $\mathrm{tm}^{-1-}$ astrocytes in normoxic conditions, the difference between the genotypes persisting also under OGD (Fig. 8A, upper panel, $B$, left panel). The increased level of HIF1 $\alpha$ in the P4h-tm ${ }^{-1-}$ astrocytes was apparently because of stabilization of the protein, since HIF1 $\alpha$ mRNA levels were similar in both genotypes (Fig. $8 C)$. Furthermore, upregulation of the SERCA2 protein correlated with an increase in HIF1 $\alpha$ stabilization (Fig. $8 A$, lower panel, $B$, right panel). To confirm the role of HIF1 in the SERCA2 regulation, we performed HIF1 $\alpha$ and HIF2 $\alpha$ siRNA knock-down experiments. The Hif1a and Hif2a expression was efficiently and specifically reduced by the siRNAs at both mRNA (Fig. 8D) and protein level (Fig. 8E). Western blotting showed that the SERCA2 protein amount in $P 4 h-\mathrm{tm}^{-1-}$ astrocytes was reduced to the WT levels or even lower in siHIF1 $\alpha$-treated cells in normoxia, while no effect was seen on siHIF2 $\alpha$ treatment (Fig. 8F). Next, we assessed whether knock-down of HIF $1 \alpha$ or HIF2 $\alpha$ affects calcium entry in $\mathrm{P} 4 \mathrm{~h}-\mathrm{tm}^{-/-}$astrocytes by performing Fluo4 time-lapse imaging $24 \mathrm{~h}$ after the transfection with siRNAs. The data show that the attenuation of ROCE in $P 4 h-\mathrm{tm}^{-1-}$ cells was reversed on treatment with $\operatorname{siHIF} 1 \alpha$, but not siHIF2 $\alpha$ (Fig. 8G). Taken together, these results indicate that the higher SERCA2 expression and reduced ROCE is mediated by stabilization of HIF1 in P4h-tm ${ }^{-1-}$ astrocytes.

\section{Discussion}

We show for the first time that $\mathrm{P} 4 \mathrm{H}-\mathrm{TM}$ is a major regulator of calcium signaling. Both ROCE and SOCE were affected in $P 4 \mathrm{~h}_{-\mathrm{tm}^{-/}}$cortical astrocytes. Furthermore, calcium-dependent agonist-induced gliotransmission was downregulated in $\mathrm{P} 4 \mathrm{~h}-\mathrm{tm}^{-1-}$ cells. siRNA data showed that $\mathrm{HIF} 1 \alpha$, but not $\mathrm{HIF} 2 \alpha$, is the principle downstream mediator of $\mathrm{P} 4 \mathrm{H}-\mathrm{TM}$ action on calcium signaling.

Several calcium sequestering ATPases, i.e., SERCA2, SERCA3, and PMCA3, were upregulated in $P 4 h-t^{-1-}$ astrocytes (Fig. $1 F-l$ ). Our results showing a decreased ATP-evoked raise of $\left[\mathrm{Ca}^{2+}\right]_{\mathrm{i}}$ in P4h-tm ${ }^{-1-}$ astrocytes (Fig. $2 B$ ) is in line with previous observations of similar calcium signaling plasticity on concomitant changes in SERCA and PMCA levels in cardiomyocytes (Ji et al., 2000), CHO cells (Brini et al., 2000), and pancreatic acinar and submandibular gland duct cells (Zhao et al., 2001).

It has been shown that PMCA and SERCA overexpression regulates the resting level of calcium in the ER of $\mathrm{CHO}$ cells in an opposite manner: higher $\left[\mathrm{Ca}^{2+}\right]_{\mathrm{er}}$ in SERCA overexpression versus lower $\left[\mathrm{Ca}^{2+}\right]_{e r}$ in PMCA overexpression (Brini et al., 2000). Our data showing a higher ionomycin-evoked increase in $\left[\mathrm{Ca}^{2+}\right]_{\mathrm{i}}$ in $\mathrm{P} 4 \mathrm{~h}-\mathrm{tm}^{-/-}$ cells (Fig. 2l, J) suggests increased $\left[\mathrm{Ca}^{2+}\right]_{\mathrm{er}}$ resting level, pointing to a major contribution of SERCA. Based on evidence provided by the GECls (Fig. 3), we suggest that in 

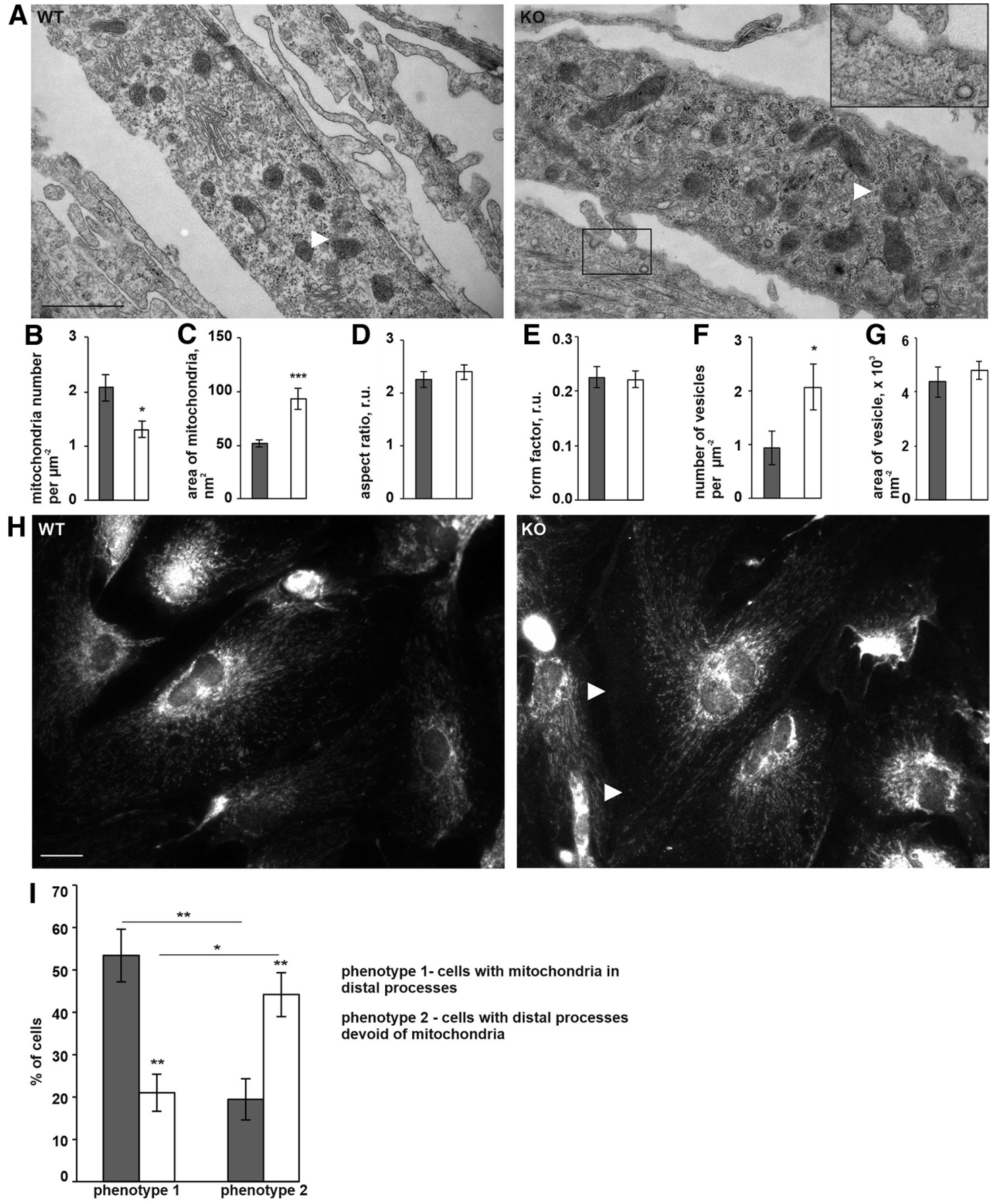

phenotype 1 - cells with mitochondria in distal processes

phenotype 2 - cells with distal processes devoid of mitochondria

$\square$ WT $\square$ Ko in B - G, F

Figure 7. $\mathrm{P} 4 \mathrm{H}-\mathrm{TM} \mathrm{KO}$ affects mitochondrial morphology and leads to accumulation of electron-lucent small vesicles (SLMVs) in the cytosol. $\boldsymbol{A}-\mathbf{G}, \mathrm{P} 4 \mathrm{H}-\mathrm{TM} \mathrm{KO}$ and WT astrocytes were analyzed by TEM. Morphometric analysis was performed on randomly selected fields. $\boldsymbol{A}$, Representative electron micrographs. Multiple mitochondria are visible (white arrows). The boxed area represents a $2.3 \times$ magnification: two SLMVs are apparent in the field of view, one of which is releasing its content to the extracellular space. Scale bar: $1 \mu \mathrm{m}$. $\boldsymbol{B}-\boldsymbol{E}$, Morphometric analysis of mitochondrial number per cell area $(\boldsymbol{B})$ and shape $(\boldsymbol{C}-\boldsymbol{E}), n=7$ astrocytes per genotype in $\boldsymbol{B}, n=84-103$ mitochondria per genotype in $\boldsymbol{C}-\boldsymbol{E}, 3$ mice per genotype. $\boldsymbol{F}, \boldsymbol{G}$, Analysis of the number $(\boldsymbol{F})$ and size $(\boldsymbol{G})$ of SLMVs; $n=7$ astrocytes per genotype in $\boldsymbol{F}, n=46$ and $n=160$ SLMVs in WT and KO cells, respectively, in G, 3 mice per genotype. $\boldsymbol{H}$, $\boldsymbol{I}$, Primary cortical astrocytes were immunostained with antiTom20 antibody for analysis of mitochondrial morphology. Representative images $(\boldsymbol{H})$ demonstrate the observed reduced mitochondrial density within the distal part of the cell processes (white arrows) in the P4H-TM KO astrocytes when compared with WT. Scale bar: $20 \mu \mathrm{m}$. The number of cells $(I)$ with clear punctate mitochondrial staining in distal processes (phenotype 1) and number of cells with distal processes virtually devoid of any staining (phenotype 2) was quantified as percent to total number of cells, $n=6-7$ cultures per genotype (corresponds to $\sim 150$ cells analyzed per genotype). Data information: data are presented as mean \pm SEM in $\boldsymbol{B}-\boldsymbol{G}, \boldsymbol{I},{ }^{\star} p<0.05$, ${ }^{\star \star \star} p<0.001$ by Student's $t$ test in $\boldsymbol{B}-\mathbf{G}$; ${ }^{*} p<0.05,{ }^{* *} p<0.01$ by Tukey's HSD test after one-way ANOVA method for multiple comparisons in $\boldsymbol{I}$. r.u., relative unit. 

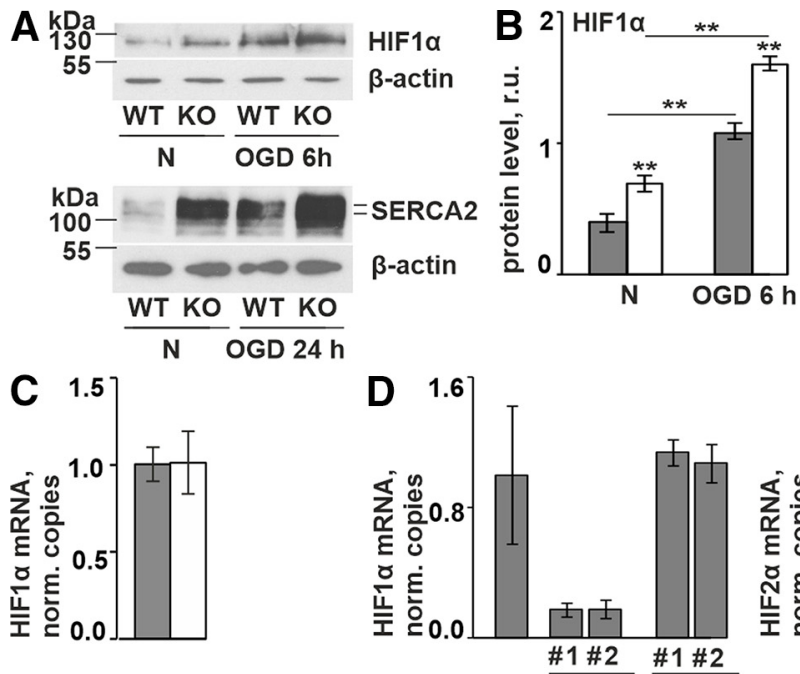

siNC $\overline{\operatorname{siHIF1\alpha }} \overline{\text { siHIF2 } \alpha}$

F kDa
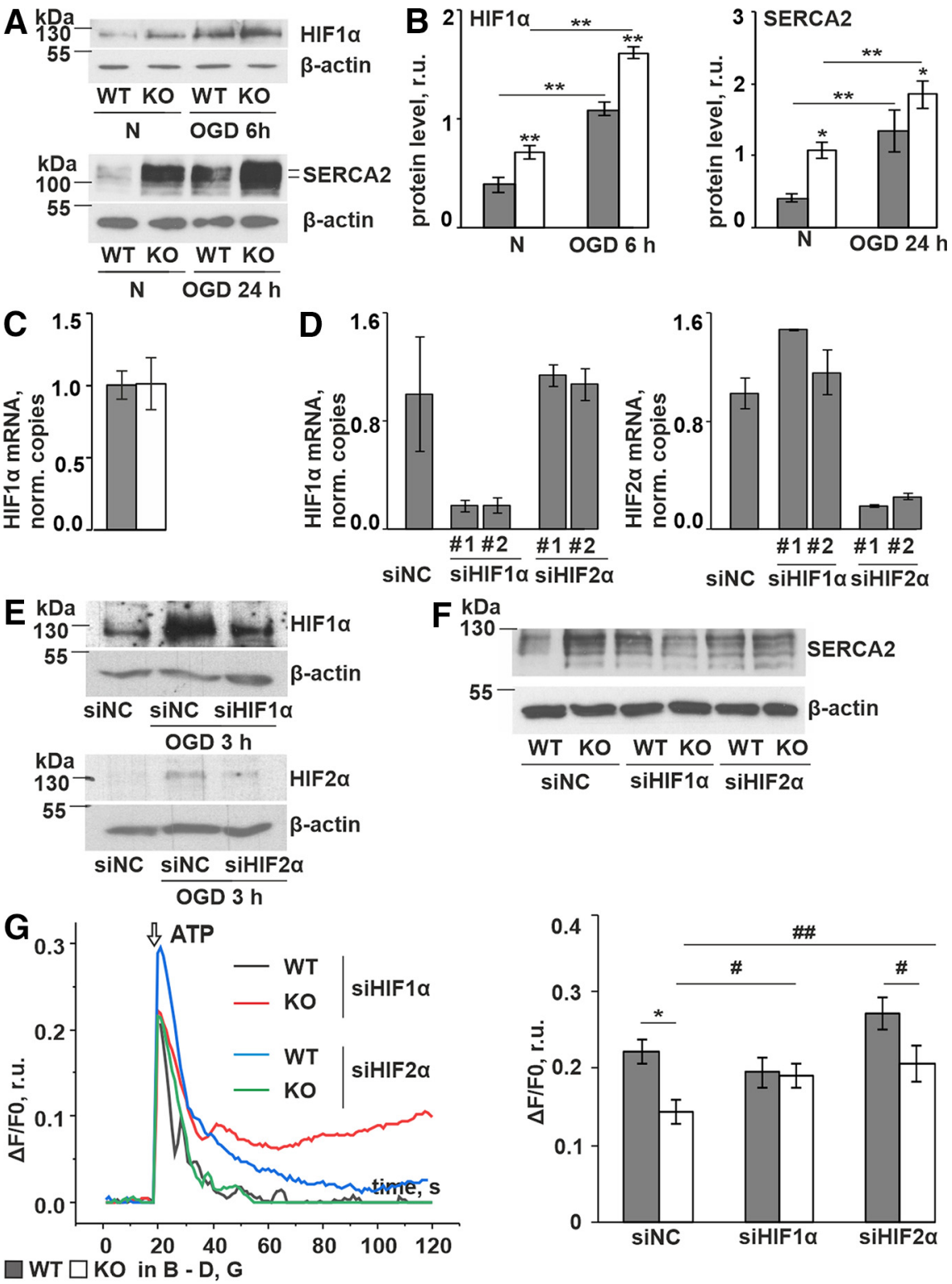

Figure 8. HIF1 mediates the $\mathrm{P} 4 \mathrm{H}-\mathrm{TM}$ effects on calcium signaling in primary cortical astrocytes. $\boldsymbol{A}, \boldsymbol{B}$, Western blot analysis of HIF1 $\alpha$ stabilization $(\boldsymbol{A}$, upper panel; $\boldsymbol{B}$, left panel) and SERCA2 protein expression (A, lower panel; $\boldsymbol{B}$, right panel) in primary cortical astrocytes incubated in normoxic $(\mathrm{N})$ or oxygen $\left(1 \% \mathrm{O}_{2}\right.$ )-glucose deprived (OGD) conditions for 6 and 24 h, respectively. Representative blots are shown in $\boldsymbol{A}$, and the intensity of bands was quantitated by densitometry $(\boldsymbol{B}), n=3$ individual cultures per genotype per condition, 6 mice per genotype. $\beta$-Actin represents a loading control in $(\boldsymbol{A})$. $\boldsymbol{C}$, qRT-PCR analysis of HIF1 $\alpha$ mRNA level in normoxic astrocytes. $\boldsymbol{D}-\mathbf{G}$, WT and P4H-TM KO astrocytes were transfected with either negative control siRNA (siNC), HIF1 $\alpha$ siRNA (siHIF1 $\alpha \# 1-2$ ) or HIF2 $\alpha$ siRNA (siHIF2 $\alpha \# 1-2$ ) and cultured for a further 24 h. D, qRT-PCR analysis of HIF1 $\alpha$ (left panel) and HIF2 $\alpha$ (right panel) mRNA levels in WT astrocytes after transfection with indicated siRNAs, $n=2$ independent cultures per siRNA. E, HIF1 $\alpha$ siRNA and HIF2 $\alpha$ siRNA transfected WT astrocytes were exposed to OGD for $3 \mathrm{~h}$ and HIF1 $\alpha$ and HIF2 $\alpha$ stabilization was analyzed by Western blotting. Representative Western blots are shown. $\beta$-Actin represents a loading control. $\boldsymbol{F}$, Representative Western blots of SERCA2 expression in siRNA-transfected cells. $\beta$-Actin represents a loading control. $\mathbf{G}$, siRNA transfected astrocytes were loaded with Fluo-4 and stimulated with $100 \mu \mathrm{M}$ ATP in a calcium-containing buffer. Representative traces of P4H-TM KO and WT astrocytes are shown on the graphs. Changes in cytosolic calcium [Ca $\left.{ }^{2+}\right]$ i peak amplitudes are shown in the diagrams. The attenuated ATP-evoked increase in $\left[\mathrm{Ca}^{2+}\right]_{\mathrm{i}}$ observed in $\mathrm{P} 4 \mathrm{H}-\mathrm{TM} \mathrm{KO}$ cells relative to WT is eliminated by siHIF1 $\alpha$ treatment, but not by siHIF2 $\alpha, n=22-33$ cells per condition. Data information: data are presented as mean \pm SEM in $\boldsymbol{B}-\boldsymbol{E}$, $G$; \#p $<0.05$, \#\#p $<0.01$ by Student's $t$ test and ${ }^{*} p<0.05$, ${ }^{\star *} p<0.01$ by Tukey's HSD test after one-way ANOVA method for multiple comparisons. r.u., relative unit. 
$P 4 h-\mathrm{tm}^{-1-}$ astrocytes ROCE is shaped by mitochondrial uptake, rather than by ER release and thus it is not proportional to the calcium content in the ER. Furthermore, it was previously shown that PMCAs can shape the pattern of calcium transients induced by SOCE (Pászty et al., 2015). Thus, in $P 4 h-\mathrm{tm}^{-1-}$ astrocytes, the enhanced increase in $\left[\mathrm{Ca}^{2+}\right]_{\mathrm{i}}$ on TG stimulation, and the substantial increase in $\left[\mathrm{Ca}^{2+}\right]_{i}$ on calcium perfusion of the cells, could be the result of enhanced expression of PMCA2 and PMCA3 (Fig. 2F, G).

Our data on increased passive leak, measured in the presence of pharmacological modulators of leak channels (Fig. $4 A, B$ ), as well as increased expression of structural components of leak channels (Fig. $4 C-E$ ), suggest a compensatory mechanism to balance calcium homeostasis with increased expression of calcium sequestering ATPases in $P 4 h-\mathrm{tm}^{-/-}$cells. Noteworthy, passive calcium leak via translocon is the first step of SOCE activation (Flourakis et al., 2006; Ong et al., 2007). Our results showing both enhanced passive leak and enhanced SOCE in P4h-tm ${ }^{-1}$ astrocytes are in line with these studies.

An increase in $\left[\mathrm{Ca}^{2+}\right]_{i}$ in astrocytes can trigger exocytotic release of gliosignals (Vardjan and Zorec, 2015). In particular, application of ATP stimulates calcium-dependent glutamate (Jeremic et al., 2001), aspartate (Duan et al., 2003), and ATP (Anderson et al., 2004; Pangrsic et al., 2007) release (Zimmermann, 2016). Calcium-dependent vesicular release of glutamate and ATP depends on the presence of the SNARE complex of proteins containing Syb2 (Zorec et al., 2012). We provide evidence using TIRF microscopy that exocytosis of Syb2-containing vesicles from astrocytes is decreased in P4h-tm ${ }^{-1-}$ cells (Fig. 5). Calcium-dependent exocytosis of gliotransmitters plays an important role in the communication between astrocytes and neurons, affects synaptic plasticity and is involved in cognitive function and several neurologic disorders (Ongür et al., 1998; Rajkowska et al., 1999; Cotter et al., 2001; Sheline et al., 2003; Banasr and Duman, 2008; Sasaki et al., 2012; Cao et al., 2013; Pannasch and Rouach, 2013). On the other hand, several steps in the vesicle release cycle are dependent on appropriate ATP levels. The supply of ATP by mitochondria is crucial for neurotransmitter release in neurons (Djeungoue-Petga and Hebert-Chatelain, 2017) and even a short interruption in ATP synthesis is sufficient to disrupt synaptic transmission in neurons (Rangaraju et al., 2014). Similarly, ATP production by mitochondria is likely to support gliotransmission in astrocytes (Jackson and Robinson, 2018). Therefore, we suggest that the observed disturbance of calcium homeostasis and modulation of intracellular ATP in P4h-tm ${ }^{-1-}$ astrocytes leads to a substantial decrease in exocytosis of gliotransmitters. This could impair the ability of $\mathrm{P} 4 \mathrm{~h}-\mathrm{tm}^{-1-}$ astrocytes to modulate neuronal activity, which should be addressed in future studies. This is of particular interest regarding the involvement of $\mathrm{P} 4 \mathrm{H}-\mathrm{TM}$ inactivation in a severe human intellectual disability syndrome (Kaasinen et al., 2014; Rahikkala et al., 2019).

ATP synthesis during oxidative phosphorylation often correlates with $\mathrm{O}_{2}$ consumption, mitochondrial membrane potential $(\Delta \Psi)$ and relative levels of fully assembled Complexes I, III, IV, and V (Schultz and Chan, 2001; Simonnet et al., 2014). Since none of these parameters

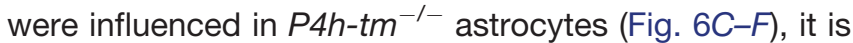
likely that the increased metabolic demands in P4h-tm ${ }^{-1-}$ astrocytes are not met by an increased production of ATP by mitochondria, and thus ultimately lead to low levels of intracellular ATP. Interestingly, although $\mathrm{P} 4 \mathrm{~h}-\mathrm{tm}^{-1-}$ cells had no effect on the $\Delta \Psi$ in normoxia, we observed a decrease in OGD-induced hyperpolarization (Fig. 6D). The mechanism of hyperpolarization is still under debate (lijima, 2006), but it has been proposed that maintenance of $\Delta \Psi$ despite respiratory inhibition is because of ATP hydrolysis by the $\mathrm{F}_{1} \mathrm{~F}_{\mathrm{O}}$-ATP synthase working in a reverse mode (Maldonado and Lemasters, 2014). Under ischemia, $\Delta \Psi$ can be maintained as long as glycolysis provides ATP (Nieminen et al., 1994). Accordingly, dissipation of the mitochondrial membrane potential seems to be a consequence of severe energy deficit (lijima, 2006). Thus, a decreased ability to maintain the hyperpolarized state of mitochondria during OGD can be related to the initial low cytosolic ATP content of normoxic P4h-tm ${ }^{-/-}$astrocytes.

Enlargement of mitochondria often parallels a decrease in the numerical density of the organelles (BertoniFreddari et al., 1993), a phenomenon observed also in P4h-tm ${ }^{-1-}$ astrocytes (Fig. 7B,C). Previously, an inverse correlation between the size and metabolic competence of mitochondria was reported in the cerebellar cortex (Bertoni-Freddari et al., 2003) and significant mitochondrial enlargement occurs on adverse cellular conditions (e.g., oxidative stress; Bertoni-Freddari et al., 1993; Karbowski et al., 1997). It is likely that the decreased number mitochondria with enlarged size is not capable to provide adequate amounts of ATP because of its higher utilization by increased expression of calcium sequestering ATPases in P4h-tm ${ }^{-1-}$ astrocytes.

A redistribution of mitochondria was observed in $P 4 h-\mathrm{tm}^{-/-}$ astrocytes (Fig. $7 H, F$ ) instead of distribution throughout the arborization. Mitochondria are actively transported to sites of elevated calcium activity both in neurons and astrocytes, where they provide local energy and directly sequester calcium, thus regulating local $\left[\mathrm{Ca}^{2+}\right]_{\mathrm{i}}$ levels (Motori et al., 2013; Stephen et al., 2015; Rivera et al., 2016; Jackson and Robinson, 2018). The main mechanism that regulates mitochondria mobility and morphology is fusion/fission (Jackson and Robinson, 2018). The lower activity in $\mathrm{P} 4 \mathrm{~h}-\mathrm{tm}^{-1-}$ astrocytes of both calcium response and vesicular exocytosis could potentially shift mitochondria mobility to prevalent fusion and thus an increase in size, accompanied with redistribution of mitochondria from the periphery toward the soma (Jackson and Robinson, 2018), but to underpin the exact molecular mechanisms responsible for the observed increase in mitochondrial size in $\mathrm{P} 4 \mathrm{~h}-\mathrm{tm}^{-1-}$ astrocytes requires further studies. Activity-dependent positioning of mitochondria is crucial for synaptic transmission in neurons (Guo et al., 2005; Verstreken et al., 2005; DjeungouePetga and Hebert-Chatelain, 2017) and a similar role of mitochondria positioning has been proposed for gliotransmission in astrocytes (Jackson and Robinson, 2018). Therefore, the decreased density of mitochondria in distal processes of $P 4 \mathrm{~h}-\mathrm{tm}^{-1-}$ astrocytes may contribute to impaired gliotransmission. The lack of mitochondria in distal 
processes of the $P 4 h-\mathrm{tm}^{-/-}$cells is especially noteworthy as emerging evidence suggests that the most important calcium transients for neuronal function occur in fine astrocyte processes, rather than in the soma (Volterra et al., 2014; Bazargani and Attwell, 2016).

Modulation of cytosolic calcium level or complete store depletion can affect HIF1 $\alpha$ stabilization (BerchnerPfannschmidt et al., 2004; Liu et al., 2004; Hui et al., 2006; Chai et al., 2016; Divolis et al., 2016). Constitutive stabilization of HIF1 $\alpha$ has been shown to result in increased SERCA2 expression and diminished calcium response on T-cell receptor stimulation in thymocytes (Neumann et al., 2005). In line with our data, HIF1 $\alpha$ was shown to mediate SERCA2b upregulation in neurons during OGD (Kopach et al., 2016). Nevertheless, although hypoxia significantly decreased the mean amplitude of caffeine-induced calcium transient in cardiomyocytes, it downregulated SERCA2 expression in these cells (Ronkainen et al., 2011; Revuelta-López et al., 2015). It is known that in cardiomyocytes, the activity of calcium pumping by SERCA2 depends on the phosphorylation status of the regulatory protein phospholamban (Haghighi et al., 2014). Thus, the different effects on SERCA2 expression by hypoxia in cardiomyocytes and $\mathrm{P} 4 \mathrm{H}-\mathrm{TM}$ inactivation in astrocytes, could be because of the different cell types investigated. Noteworthy, it has been shown that a combined deletion of HIF-P4H-2 and HIF-P4H-3 and hence HIF1 $\alpha$ stabilization in cardiomyocytes leads to a drastic decrease in phospholamban expression (Xie et al., 2015). In addition, HIF1 $\alpha$ was recently shown to directly regulate key proteins involved in SOCE, such as different isoforms of STIM and Orai, thus mediating enhanced SOCE under hypoxic conditions in several cell types (Li et al., 2015). We demonstrate here that HIF1 $\alpha$ is a key mediator of SERCA2 overexpression as well as decreased ROCE in P4h-tm ${ }^{-1-}$ astrocytes, while HIF2 $\alpha$ does not play a role (Fig. 8).

Taken together, our study identifies $\mathrm{P} 4 \mathrm{H}-\mathrm{TM}$ as a novel regulator of several aspects of calcium signaling in astrocytes. In addition, we show that HIF1 $\alpha$ is the key mediator between $\mathrm{P} 4 \mathrm{H}-\mathrm{TM}$ and calcium signaling. Besides the microarray analysis of the whole cortex and qRT-PCR analyses of selected key genes in the astrocytes reported in this study, transcriptome analysis of the WT and P4h-tm ${ }^{-1-}$ astrocytes either by microarray analysis or RNA-seq would be of interest in the future to reveal possible further effects of P4H-TM on genes involved in calcium signaling. In addition, whether inactivation of $\mathrm{P} 4 \mathrm{H}-\mathrm{TM}$ has similar effects on calcium signaling in other cell types remains to be studied. Furthermore, future studies are required to analyze what effects $\mathrm{P} 4 \mathrm{H}-\mathrm{TM}$ has on astrocyte functions in for example various disease settings, and to what extent they are caused by the effects on calcium signaling observed in this study. For example, it will be of interest to determine whether the observed effects of $\mathrm{P} 4 \mathrm{H}-\mathrm{TM}$ on calcium signaling and vesicular transport will provide novel information on the etiology of the human HIDEA disease caused by P4H-TM mutations (Kaasinen et al., 2014; Rahikkala et al., 2019) and the behavioral phenotype of increased social behavior, decreased anxiety, and absence of despair of the P4h-tm ${ }^{-1-}$ mice (Leinonen et al., 2019).

\section{References}

Aakalu G, Smith WB, Nguyen N, Jiang C, Schuman EM (2001) Dynamic visualization of local protein synthesis in hippocampal neurons. Neuron 30:489-502.

Anderson CM, Bergher JP, Swanson RA (2004) ATP-induced ATP release from astrocytes. J Neurochem 88:246-256.

Banasr M, Duman RS (2008) Glial loss in the prefrontal cortex is sufficient to induce depressive-like behaviors. Biol Psychiatry 64:863870.

Bazargani N, Attwell D (2016) Astrocyte calcium signaling: the third wave. Nat Neurosci 19:182-189.

Berchner-Pfannschmidt U, Petrat F, Doege K, Trinidad B, Freitag P, Metzen E, de Groot H, Fandrey J (2004) Chelation of cellular calcium modulates hypoxia-inducible gene expression through activation of hypoxia-inducible factor-1alpha. J Biol Chem 279:44976-44986.

Berridge MJ, Lipp P, Bootman MD (2000) The versatility and universality of calcium signalling. Nat Rev Mol Cell Biol 1:11-21.

Bertoni-Freddari C, Fattoretti P, Casoli T, Spagna C, Meier-Ruge W, Ulrich J (1993) Compensatory enlargement of synaptic size in aging and senile dementia. Boll Soc Ital Biol Sper 69:57-63.

Bertoni-Freddari C, Fattoretti P, Paoloni R, Caselli U, Giorgetti B, Solazzi M (2003) Inverse correlation between mitochondrial size and metabolic competence: a quantitative cytochemical study of cytochrome oxidase activity. Naturwissenschaften 90:68-71.

Bezzi P, Volterra A (2001) A neuron-glia signalling network in the active brain. Curr Opin Neurobiol 11:387-394.

Bootman MD, Collins TJ, Mackenzie L, Roderick HL, Berridge MJ, Peppiatt CM (2002) 2-Aminoethoxydiphenyl borate (2-APB) is a reliable blocker of store-operated $\mathrm{Ca}^{2+}$ entry but an inconsistent inhibitor of InsP $\mathrm{P}_{3}$-induced $\mathrm{Ca}^{2+}$ release. FASEB J 16:1145-1150.

Brini M, Bano D, Manni S, Rizzuto R, Carafoli E (2000) Effects of PMCA and SERCA pump overexpression on the kinetics of cell $\mathrm{Ca}$ $(2+)$ signalling. EMBO J 19:4926-4935.

Calloway N, Holowka D, Baird B (2010) A basic sequence in STIM1 promotes $\mathrm{Ca}^{2+}$ influx by interacting with the C-terminal acidic coiled coil of Orai1. Biochemistry 49:1067-1071.

Cao X, Li LP, Wang Q, Wu Q, Hu HH, Zhang M, Fang YY, Zhang J, Li SJ, Xiong WC, Yan HC, Gao YB, Liu JH, Li XW, Sun LR, Zeng YN, Zhu XH, Gao TM (2013) Astrocyte-derived ATP modulates depressive-like behaviors. Nat Med 19:773-777.

Chai D, Jiang H, Li Q (2016) Isoflurane neurotoxicity involves activation of hypoxia inducible factor- $1 \alpha$ via intracellular calcium in neonatal rodents. Brain Res 1653:39-50.

Clapham DE (2007) Calcium signaling. Cell 131:1047-1058.

Claydon AJ, Beynon R (2012) Proteome dynamics: revisiting turnover with a global perspective. Mol Cell Proteomics 11:15511565.

Cotter D, Mackay D, Landau S, Kerwin R, Everall I (2001) Reduced glial cell density and neuronal size in the anterior cingulate cortex in major depressive disorder. Arch Gen Psychiatry 58:545-553.

Darling NJ, Cook SJ (2014) The role of MAPK signalling pathways in the response to endoplasmic reticulum stress. Biochim Biophys Acta 1843:2150-2163.

Davey GP, Clark JB (1996) Threshold effects and control of oxidative phosphorylation in nonsynaptic rat brain mitochondria. $\mathrm{J}$ Neurochem 66:1617-1624.

Divolis G, Mavroeidi P, Mavrofrydi O, Papazafiri P (2016) Differential effects of calcium on PI3K-Akt and HIF- $1 \alpha$ survival pathways. Cell Biol Toxicol 32:437-449.

Djeungoue-Petga MA, Hebert-Chatelain E (2017) Linking mitochondria and synaptic transmission: the CB1 receptor. Bioessays 39:1700126.

Duan S, Anderson CM, Keung EC, Chen Y, Chen Y, Swanson RA (2003) P2X7 receptor-mediated release of excitatory amino acids from astrocytes. J Neurosci 23:1320-1328.

Edgar R, Domrachev M, Lash AE (2002) Gene Expression Omnibus: NCBI gene expression and hybridization array data repository. Nucleic Acids Res 30:207-210. 
Ehrenberg B, Montana V, Wei MD, Wuskell JP, Loew LM (1988) Membrane potential can be determined in individual cells from the nernstian distribution of cationic dyes. Biophys J 53:785-794.

Filadi R, Theurey P, Pizzo P (2017) The endoplasmic reticulum-mitochondria coupling in health and disease: molecules, functions and significance. Cell Calcium 62:1-15.

Fischer W, Appelt K, Grohmann M, Franke H, Nörenberg W, Illes P (2009) Increase of intracellular $\mathrm{Ca}^{2+}$ by P2X and P2Y receptorsubtypes in cultured cortical astroglia of the rat. Neuroscience 160:767-783.

Flourakis M, Van Coppenolle F, Lehen'kyi V, Beck B, Skryma R, Prevarskaya N (2006) Passive calcium leak via translocon is a first step for iPLA2-pathway regulated store-operated channels activation. FASEB J 20:1215-1217.

Gao X, Xia J, Munoz FM, Manners MT, Pan R, Meucci O, Dai Y, Hu H (2016) STIMs and Orai1 regulate cytokine production in spinal astrocytes. J Neuroinflammation 13:126.

Guo X, Macleod GT, Wellington A, Hu F, Panchumarthi S, Schoenfield M, Marin L, Charlton MP, Atwood HL, Zinsmaier KE (2005) The GTPase dMiro is required for axonal transport of mitochondria to Drosophila synapses. Neuron 47:379-393.

Haghighi K, Bidwell P, Kranias EG (2014) Phospholamban interactome in cardiac contractility and survival: a new vision of an old friend. J Mol Cell Cardiol 77:160-167.

Huang Y, Li X, Wang Y, Wang H, Huang C, Li J (2014) Endoplasmic reticulum stress-induced hepatic stellate cell apoptosis through calcium-mediated JNK/P38 MAPK and Calpain/Caspase-12 pathways. Mol Cell Biochem 394:1-12.

Hui AS, Bauer AL, Striet JB, Schnell PO, Czyzyk-Krzeska MF (2006) Calcium signaling stimulates translation of $\mathrm{HIF}-\alpha$ during hypoxia. FASEB J 20:466-475.

Hyvärinen J, Hassinen IE, Sormunen R, Mäki JM, Kivirikko KI, Koivunen P, Myllyharju J (2010) Hearts of hypoxia-inducible factor prolyl 4-hydroxylase-2 hypomorphic mice show protection against acute ischemia-reperfusion injury. J Biol Chem 285:13646-13657.

lijima T (2006) Mitochondrial membrane potential and ischemic neuronal death. Neurosci Res 55:234-243.

Ivan M, Kaelin WG Jr (2017) The EGLN-HIF $\mathrm{O}_{2}$-sensing system: multiple inputs and feedbacks. Mol Cell 66:772-779.

Jackson JG, Robinson MB (2018) Regulation of mitochondrial dynamics in astrocytes: mechanisms, consequences, and unknowns. Glia 66:1213-1234.

Jeremic A, Jeftinija K, Stevanovic J, Glavaski A, Jeftinija S (2001) ATP stimulates calcium-dependent glutamate release from cultured astrocytes. J Neurochem 77:664-675.

Ji Y, Lalli MJ, Babu GJ, Xu Y, Kirkpatrick DL, Liu LH, Chiamvimonvat N, Walsh RA, Shull GE, Periasamy M (2000) Disruption of a single copy of the SERCA2 gene results in altered $\mathrm{Ca}^{2+}$ homeostasis and cardiomyocyte function. J Biol Chem 275:38073-38080.

Johnson GG, White MC, Wu JH, Vallejo M, Grimaldi M (2014) The deadly connection between endoplasmic reticulum, $\mathrm{Ca}^{2+}$, protein synthesis, and the endoplasmic reticulum stress response in malignant glioma cells. Neuro Oncol 16:1086-1099.

Kaasinen E, Rahikkala E, Koivunen P, Miettinen S, Wamelink MM, Aavikko M, Palin K, Myllyharju J, Moilanen JS, Pajunen L, Karhu A, Aaltonen LA (2014) Clinical characterization, genetic mapping and whole-genome sequence analysis of a novel autosomal recessive intellectual disability syndrome. Eur J Med Genet 57:543-551.

Kadenbach B, Ramzan R, Moosdorf R, Vogt S (2011) The role of mitochondrial membrane potential in ischemic heart failure. Mitochondrion 11:700-706.

Kamiya T, Obara A, Hara H, Inagaki N, Adachi T (2011) ER stress inducer, thapsigargin, decreases extracellular-superoxide dismutase through MEK/ERK signalling cascades in COS7 cells. Free Radic Res 45:692-698.

Karbowski M, Kurono C, Nishizawa Y, Horie Y, Soji T, Wakabayashi T (1997) Induction of megamitochondria by some chemicals inducing oxidative stress in primary cultured rat hepatocytes. Biochim Biophys Acta 1349:242-250.
Kim DS, Kim JH, Lee GH, Kim HT, Lim JM, Chae SW, Chae HJ, Kim HR (2010) p38 Mitogen-activated protein kinase is involved in endoplasmic reticulum stress-induced cell death and autophagy in human gingival fibroblasts. Biol Pharm Bull 33:545-549.

King BF, Neary JT, Zhu Q, Wang S, Norenberg MD, Burnstock G (1996) P2 purinoceptors in rat cortical astrocytes: expression, calcium-imaging and signalling studies. Neuroscience 74:11871196.

Klotzsche-von Ameln A, Prade I, Grosser M, Kettelhake A, Rezaei M, Chavakis T, Flamme I, Wielockx B, Breier G (2013) PHD4 stimulates tumor angiogenesis in osteosarcoma cells via TGF- $\alpha$. Mol Cancer Res 11:1337-1348.

Koivunen P, Tiainen P, Hyvärinen J, Williams KE, Sormunen R, Klaus SJ, Kivirikko KI, Myllyharju J (2007) An endoplasmic reticulum transmembrane prolyl 4-hydroxylase is induced by hypoxia and acts on hypoxia-inducible factor $\alpha$. J Biol Chem 282:3054430552.

Konzack A, Jakupovic M, Kubaichuk K, Görlach A, Dombrowski F, Miinalainen I, Sormunen R, Kietzmann T (2015) Mitochondrial dysfunction due to lack of manganese superoxide dismutase promotes hepatocarcinogenesis. Antioxid Redox Signal 23:10591075.

Kopach O, Maistrenko A, Lushnikova I, Belan P, Skibo G, Voitenko N (2016) HIF-1 $\alpha$-mediated upregulation of SERCA2b: the endogenous mechanism for alleviating the ischemia-induced intracellular $\mathrm{Ca}^{2+}$ store dysfunction in CA1 and CA3 hippocampal neurons. Cell Calcium 59:251-261.

Korenić A, Boltze J, Deten A, Peters M, Andjus P, Radenović L (2014) Astrocytic mitochondrial membrane hyperpolarization following extended oxygen and glucose deprivation. PLoS One 9:e90697.

Kreft M, Stenovec M, Rupnik M, Grilc S, Krzan M, Potokar M, Pangrsic T, Haydon PG, Zorec R (2004) Properties of Ca(2+)-dependent exocytosis in cultured astrocytes. Glia 46:437-445.

Kwon J, An H, Sa M, Won J, Shin JI, Lee CJ (2017) Orai1 and Orai3 in combination with Stim1 mediate the majority of store-operated calcium entry in astrocytes. Exp Neurobiol 26:42-54.

Laitala A, Aro E, Walkinshaw G, Mäki JM, Rossi M, Heikkilä M, Savolainen ER, Arend M, Kivirikko KI, Koivunen P, Myllyharju J (2012) Transmembrane prolyl 4-hydroxylase is a fourth prolyl 4-hydroxylase regulating EPO production and erythropoiesis. Blood 120:3336-3344.

Lalo U, Rasooli-Nejad S, Pankratov Y (2014) Exocytosis of gliotransmitters from cortical astrocytes: implications for synaptic plasticity and aging. Biochem Soc Trans 42:1275-1281.

Lang S, Pfeffer S, Lee PH, Cavalié A, Helms V, Förster F, Zimmermann R (2017) An update on Sec61 channel functions, mechanisms, and related diseases. Front Physiol 8:887.

Leinonen $\mathrm{H}$, Rossi M, Salo AM, Tiainen P, Hyvärinen J, Pitkänen M, Sormunen R, Miinalainen I, Zhang C, Soininen R, Kivirikko KI, Koskelainen A, Tanila H, Myllyharju J, Koivunen P (2016) Lack of $\mathrm{P} 4 \mathrm{H}-\mathrm{TM}$ in mice results in age-related retinal and renal alterations. Hum Mol Genet 25:3810-3823.

Leinonen $H$, Koivisto $H$, Lipponen HR, Matilainen A, Salo AM, Dimova $E Y$, Hämäläinen $E$, Stavén $S$, Miettinen $P$, Koivunen $P$, Myllyharju J, Tanila H (2019) Null mutation in P4h-tm leads to decreased fear and anxiety and increased social behavior in mice. Neuropharmacology 153:63-72.

Li Y, Guo B, Xie Q, Ye D, Zhang D, Zhu Y, Chen H, Zhu B (2015) STIM1 mediates hypoxia-driven hepatocarcinogenesis via interaction with HIF-1. Cell Rep 12:388-395.

Liu Q, Möller U, Flugel D, Kietzmann T (2004) Induction of plasminogen activator inhibitor I gene expression by intracellular calcium via hypoxia-inducible factor-1. Blood 104:3993-4001.

Maldonado EN, Lemasters JJ (2014) ATP/ADP ratio, the missed connection between mitochondria and the Warburg effect. Mitochondrion 19:78-84

Mallilankaraman K, Cárdenas C, Doonan PJ, Chandramoorthy HC, Irrinki KM, Golenár T, Csordás G, Madireddi P, Yang J, Müller M, Miller R, Kolesar JE, Molgó J, Kaufman B, Hajnóczky G, Foskett JK, Madesh M (2012a) MCUR1 is an essential component of 
mitochondrial $\mathrm{Ca}^{2+}$ uptake that regulates cellular metabolism. Nat Cell Biol 14:1336-1343.

Mallilankaraman K, Doonan P, Cárdenas C, Chandramoorthy HC, Müller M, Miller R, Hoffman NE, Gandhirajan RK, Molgó J, Birnbaum MJ, Rothberg BS, Mak DO, Foskett JK, Madesh M (2012b) MICU1 is an essential gatekeeper for MCU-mediated mitochondrial $\mathrm{Ca}(2+)$ uptake that regulates cell survival. Cell 151:630-644.

Martin-Jiménez CA, García-Vega Á, Cabezas R, Aliev G, Echeverria V, González J, Barreto GE (2017) Astrocytes and endoplasmic reticulum stress: a bridge between obesity and neurodegenerative diseases. Prog Neurobiol 158:45-68.

McCarthy KD, de Vellis J (1980) Preparation of separate astroglial and oligodendroglial cell cultures from rat cerebral tissue. J Cell Biol 85:890-902.

McCollum AT, Jafarifar F, Chan R, Guttmann RP (2004) Oxidative stress inhibits ionomycin-mediated cell death in cortical neurons. J Neurosci Res 76:104-109.

Miesenböck G, De Angelis DA, Rothman JE (1998) Visualizing secretion and synaptic transmission with $\mathrm{pH}$-sensitive green fluorescent proteins. Nature 394:192-195.

Montana V, Malarkey EB, Verderio C, Matteoli M, Parpura V (2006) Vesicular transmitter release from astrocytes. Glia 54:700-715.

Mortiboys H, Thomas KJ, Koopman WJ, Klaffke S, Abou-Sleiman P, Olpin S, Wood NW, Willems PH, Smeitink JA, Cookson MR, Bandmann O (2008) Mitochondrial function and morphology are impaired in parkin-mutant fibroblasts. Ann Neurol 64:555-565.

Motori E, Puyal J, Toni N, Ghanem A, Angeloni C, Malaguti M, Cantelli-Forti G, Berninger B, Conzelmann KK, Götz M, Winklhofer KF, Hrelia S, Bergami M (2013) Inflammation-induced alteration of astrocyte mitochondrial dynamics requires autophagy for mitochondrial network maintenance. Cell Metab 18:844-859.

Müller MS, Obel LF, Waagepetersen HS, Schousboe A, Bak LK (2013) Complex actions of ionomycin in cultured cerebellar astrocytes affecting both calcium-induced calcium release and storeoperated calcium entry. Neurochem Res 38:1260-1265.

Myllyharju J (2008) Prolyl 4-hydroxylases, key enzymes in the synthesis of collagens and regulation of the response to hypoxia, and their roles as treatment targets. Ann Med 40:402-417.

Myllyharju J (2013) Prolyl 4-hydroxylases, master regulators of the hypoxia response. Acta Physiol (Oxf) 208:148-165.

Myllyharju J, Kivirikko KI (1999) Identification of a novel proline-rich peptide-binding domain in prolyl 4-hydroxylase. EMBO J 18:306312.

Neumann AK, Yang J, Biju MP, Joseph SK, Johnson RS, Haase VH, Freedman BD, Turka LA (2005) Hypoxia inducible factor 1alpha regulates $T$ cell receptor signal transduction. Proc Natl Acad Sci USA 102:17071-17076.

Nieminen AL, Saylor AK, Herman B, Lemasters JJ (1994) ATP depletion rather than mitochondrial depolarization mediates hepatocyte killing after metabolic inhibition. Am J Physiol 267:C67-74.

Nijtmans LG, Henderson NS, Holt IJ (2002) Blue native electrophoresis to study mitochondrial and other protein complexes. Methods 26:327-334.

Oehme F, Ellinghaus P, Kolkhof P, Smith TJ, Ramakrishnan S, Hütter J, Schramm M, Flamme I (2002) Overexpression of PH-4, a novel putative proline 4-hydroxylase, modulates activity of hypoxia-inducible transcription factors. Biochem Biophys Res Commun 296:343-349.

Oliet SH, Piet R, Poulain DA (2001) Control of glutamate clearance and synaptic efficacy by glial coverage of neurons. Science 292:923-926.

Ong HL, Liu X, Sharma A, Hegde RS, Ambudkar IS (2007) Intracellular $\mathrm{Ca}(2+)$ release via the $\mathrm{ER}$ translocon activates storeoperated calcium entry. Pflugers Arch 453:797-808.

Ongür D, Drevets WC, Price JL (1998) Glial reduction in the subgenual prefrontal cortex in mood disorders. Proc Natl Acad Sci USA 95:13290-13295.

Pangrsic T, Potokar M, Stenovec M, Kreft M, Fabbretti E, Nistri A, Pryazhnikov E, Khiroug L, Giniatullin R, Zorec R (2007) Exocytotic release of ATP from cultured astrocytes. J Biol Chem 282:2874928758.

Pannasch U, Rouach N (2013) Emerging role for astroglial networks in information processing: from synapse to behavior. Trends Neurosci 36:405-417.

Papanikolaou M, Lewis A, Butt AM (2017) Store-operated calcium entry is essential for glial calcium signalling in CNS white matter. Brain Struct Funct 222:2993-3005.

Parpura V, Zorec R (2010) Gliotransmission: exocytotic release from astrocytes. Brain Res Rev 63:83-92.

Pászty K, Caride AJ, Bajzer Ž, Offord CP, Padányi R, Hegedús L, Varga K, Strehler EE, Enyedi A (2015) Plasma membrane $\mathrm{Ca}^{2+}$ ATPases can shape the pattern of $\mathrm{Ca}^{2+}$ transients induced by store-operated $\mathrm{Ca}^{2+}$ entry. Sci Signal 8:ra19.

Perocchi F, Gohil VM, Girgis HS, Bao XR, McCombs JE, Palmer AE, Mootha VK (2010) MICU1 encodes a mitochondrial EF hand protein required for $\mathrm{Ca}(2+)$ uptake. Nature 467:291-296.

Rahikkala E, Myllykoski M, Hinttala R, Vieira P, Nayebzadeh N, Weiss S, Plomp AS, Bittner RE, Kurki MI, Kuismin O, Lewis AM, Väisänen ML, Kokkonen H, Westermann J, Bernert G, Tuominen H, Palotie A, Aaltonen L, Yang Y, Potocki L, et al. (2019) Biallelic loss-offunction P4HTM gene variants cause hypotonia, hypoventilation, intellectual disability, dysautonomia, epilepsy, and eye abnormalities (HIDEA syndrome). Genet Med 21:2355-2363.

Rajkowska G, Miguel-Hidalgo JJ, Wei J, Dilley G, Pittman SD, Meltzer HY, Overholser JC, Roth BL, Stockmeier CA (1999) Morphometric evidence for neuronal and glial prefrontal cell pathology in major depression. Biol Psychiatry 45:1085-1098.

Rangaraju V, Calloway N, Ryan TA (2014) Activity-driven local ATP synthesis is required for synaptic function. Cell 156:825-835.

Rao W, Zhang L, Peng C, Hui H, Wang K, Su N, Wang L, Dai SH, Yang YF, Chen T, Luo P, Fei Z (2015) Downregulation of STIM2 improves neuronal survival after traumatic brain injury by alleviating calcium overload and mitochondrial dysfunction. Biochim Biophys Acta 1852:2402-2413.

Ratcliffe PJ (2013) Oxygen sensing and hypoxia signalling pathways in animals: the implications of physiology for cancer. J Physiol 591:2027-2042.

Reich M, Liefeld T, Gould J, Lerner J, Tamayo P, Mesirov JP (2006) GenePattern 2.0. Nat Genet 38:500-501.

Revuelta-López E, Cal R, Herraiz-Martínez A, de Gonzalo-Calvo D, Nasarre L, Roura S, Gálvez-Montón C, Bayes-Genis A, Badimon L, Hove-Madsen L, Llorente-Cortés V (2015) Hypoxia-driven sarcoplasmic/endoplasmic reticulum calcium ATPase 2 (SERCA2) downregulation depends on low-density lipoprotein receptor-related protein 1 (LRP1)-signalling in cardiomyocytes. J Mol Cell Cardiol 85:25-36.

Rivera A, Vanzulli I, Butt AM (2016) A central role for ATP signalling in glial interactions in the CNS. Curr Drug Targets 17:1829-1833.

Ronkainen VP, Skoumal R, Tavi PJ (2011) Hypoxia and HIF-1 suppress SERCA2a expression in embryonic cardiac myocytes through two interdependent hypoxia response elements. J Mol Cell Cardiol 50:1008-1016.

Royle SJ, Granseth B, Odermatt B, Derevier A, Lagnado L (2008) Imaging phluorin-based probes at hippocampal synapses. Methods Mol Biol 457:293-303.

Salin K, Auer SK, Rey B, Selman C, Metcalfe NB (2015) Variation in the link between oxygen consumption and ATP production, and its relevance for animal performance. Proc Biol Sci 282:2015-1028.

Sankaranarayanan S, De Angelis D, Rothman JE, Ryan TA (2000) The use of pHluorins for optical measurements of presynaptic activity. Biophys J 79:2199-2208.

Sasaki T, Beppu K, Tanaka KF, Fukazawa Y, Shigemoto R, Matsui K (2012) Application of an optogenetic byway for perturbing neuronal activity via glial photostimulation. Proc Natl Acad Sci USA 109:20720-20725.

Schindelin J, Arganda-Carreras I, Frise E, Kaynig V, Longair M, Pietzsch T, Preibisch S, Rueden C, Saalfeld S, Schmid B, Tinevez JY, White DJ, Hartenstein V, Eliceiri K, Tomancak P, Cardona A 
(2012) Fiji: an open-source platform for biological-image analysis. Nat Methods 9:676-682.

Schultz BE, Chan SI (2001) Structures and proton-pumping strategies of mitochondrial respiratory enzymes. Annu Rev Biophys Biomol Struct 30:23-65.

Scott AL, Zhang M, Nurse CA (2015) Enhanced BDNF signalling following chronic hypoxia potentiates catecholamine release from cultured rat adrenal chromaffin cells. J Physiol 593:3281-3299.

Semenza GL, Prabhakar NR (2015) Neural regulation of hypoxia-inducible factors and redox state drives the pathogenesis of hypertension in a rodent model of sleep apnea. J Appl Physiol (1985) 119:1152-1156.

Sheline YI, Gado MH, Kraemer HC (2003) Untreated depression and hippocampal volume loss. Am J Psychiatry 160:1516-1518.

Simonnet H, Vigneron A, Pouysségur J (2014) Conventional techniques to monitor mitochondrial oxygen consumption. Methods Enzymol 542:151-161.

Smith HL, Freeman OJ, Butcher AJ, Holmqvist S, Humoud I, Schätzl T, Hughes DT, Verity NC, Swinden DP, Hayes J, de Weerd L, Rowitch DH, Franklin RJM, Mallucci GR (2020) Astrocyte unfolded protein response induces a specific reactivity state that causes non-cell-autonomous neuronal degeneration. Neuron 105:855866.

Smith IC, Bombardier E, Vigna C, Tupling AR (2013) ATP consumption by sarcoplasmic reticulum $\mathrm{Ca}^{2+}$ pumps accounts for $40-50 \%$ of resting metabolic rate in mouse fast and slow twitch skeletal muscle. PLoS One 8:e68924.

Stephen TL, Higgs NF, Sheehan DF, Al Awabdh S, López-Doménech G, Arancibia-Carcamo IL, Kittler JT (2015) Miro1 regulates activitydriven positioning of mitochondria within astrocytic processes apposed to synapses to regulate intracellular calcium signaling. $J$ Neurosci 35:15996-16011.

Suzuki J, Kanemaru K, Ishii K, Ohkura M, Okubo Y, lino M (2014) Imaging intraorganellar $\mathrm{Ca}^{2+}$ at subcellular resolution using CEPIA. Nat Commun 5:4153.

Suzuki J, Kanemaru K, lino M (2016) Genetically encoded fluorescent indicators for organellar calcium imaging. Biophys $\mathrm{J}$ 111:11191131.

Szlufcik K, Missiaen L, Parys JB, Callewaert G, De Smedt H (2006) Uncoupled IP3 receptor can function as a $\mathrm{Ca}^{2+}$-leak channel: cell biological and pathological consequences. Biol Cell 98:1-14.
Terunuma M, Haydon PG, Pangalos MN, Moss SJ (2015) Purinergic receptor activation facilitates astrocytic GABAB receptor calcium signalling. Neuropharmacology 88:74-81.

Ugalde C, Janssen RJ, van den Heuvel LP, Smeitink JA, Nijtmans LG (2004) Differences in assembly or stability of complex I and other mitochondrial OXPHOS complexes in inherited complex I deficiency. Hum Mol Genet 13:659-667.

Ullah K, Rosendahl AH, Izzi V, Bergmann U, Pihlajaniemi T, Mäki JM, Myllyharju J (2017) Hypoxia-inducible factor prolyl-4-hydroxylase1 is a convergent point in the reciprocal negative regulation of NF$\kappa \mathrm{B}$ and p53 signaling pathways. Sci Rep 7:17220.

Van Coppenolle F, Vanden Abeele F, Slomianny C, Flourakis M, Hesketh J, Dewailly E, Prevarskaya N (2004) Ribosome-translocon complex mediates calcium leakage from endoplasmic reticulum stores. J Cell Sci 117:4135-4142.

Vardjan N, Zorec R (2015) Excitable astrocytes: $\mathrm{Ca}(2+)$ - and cAMPregulated exocytosis. Neurochem Res 40:2414-2424.

Verstreken P, Ly CV, Venken KJ, Koh TW, Zhou Y, Bellen HJ (2005) Synaptic mitochondria are critical for mobilization of reserve pool vesicles at Drosophila neuromuscular junctions. Neuron 47:365378.

Volterra A, Liaudet N, Savtchouk I (2014) Astrocyte Ca(2+) signalling: an unexpected complexity. Nat Rev Neurosci 15:327-335.

Xie L, Pi X, Townley-Tilson WH, Li N, Wehrens XH, Entman ML, Taffet GE, Mishra A, Peng J, Schisler JC, Meissner G, Patterson C (2015) PHD2/3-dependent hydroxylation tunes cardiac response to $\beta$-adrenergic stress via phospholamban. J Clin Invest 125:2759-2771.

Zhao XS, Shin DM, Liu LH, Shull GE, Muallem S (2001) Plasticity and adaptation of $\mathrm{Ca}^{2+}$ signaling and $\mathrm{Ca}^{2+}$-dependent exocytosis in SERCA2 ${ }^{+/-}$mice. EMBO J 20:2680-2689.

Zimmermann H (2016) Extracellular ATP and other nucleotides-ubiquitous triggers of intercellular messenger release. Purinergic Signal 12:25-57.

Zorec R, Araque A, Carmignoto G, Haydon PG, Verkhratsky A, Parpura V (2012) Astroglial excitability and gliotransmission: an appraisal of $\mathrm{Ca} 2+$ as a signalling route. ASN Neuro 4:e00080.

Zorec R, Verkhratsky A, Rodríguez JJ, Parpura V (2016) Astrocytic vesicles and gliotransmitters: slowness of vesicular release and synaptobrevin2-laden vesicle nanoarchitecture. Neuroscience 323:67-75. 